\title{
YAP-Dependent BiP Induction Is Involved in Nicotine-Mediated Oral Cancer Malignancy
}

\author{
Chu-Yen Chien ${ }^{1}$, Ying-Chen Chen ${ }^{2}$, Chia-Chen Hsu ${ }^{1}$, Yu-Ting Chou ${ }^{3}$, Shine-Gwo Shiah ${ }^{4}{ }^{\oplus}$, Shyun-Yeu Liu ${ }^{5}$, \\ Alexander Cheng-Ting Hsieh ${ }^{6}$, Ching-Yu Yen ${ }^{5,7, *}$, Chien-Hsing Lee ${ }^{8,9, *}$ and Yi-Shing Shieh ${ }^{9,10, *}$ \\ 1 Graduate Institute of Medical Sciences, National Defense Medical Center, Taipei 114, Taiwan; \\ pooh.chien@gmail.com (C.-Y.C.); because0517@gmail.com (C.-C.H.) \\ 2 Molecular and Cell Biology, Taiwan International Graduate Program, Academia Sinica and Graduate Institute \\ of Life Science, National Defense Medical Center, Taipei 114, Taiwan; jamiechen1027@gmail.com \\ 3 Institute of Biotechnology, National Tsing Hua University, Hsinchu 300, Taiwan; ytchou@life.nthu.edu.tw \\ 4 National Institute of Cancer Research, National Health Research Institutes, Miaoli 350, Taiwan; \\ davidssg@nhri.edu.tw \\ 5 Department of Oral and Maxillofacial Surgery, Chi Mei Medical Center, Tainan 710, Taiwan; \\ syliu@mail.chimei.org.tw \\ 6 School of Traditional Chinese Medicine, Chang Gung University, Taoyuan 333, Taiwan; \\ alexsctshieh@gmail.com \\ 7 School of Dentistry, Taipei Medical University, Taipei 110, Taiwan \\ 8 Division of Endocrinology and Metabolism, Department of Internal Medicine, Tri-Service General Hospital, \\ National Defense Medical Center, Taipei 114, Taiwan \\ 9 Department and Graduate Institute of Biochemistry, National Defense Medical Center, Taipei 114, Taiwan \\ 10 Department of Dentistry, Tri-Service General Hospital, National Defense Medical Center, Taipei 114, Taiwan \\ check for \\ updates \\ Citation: Chien, C.-Y.; Chen, Y.-C.; \\ * Correspondence: ycy@tmu.edu.tw (C.-Y.Y.); doc10383@gmail.com (C.-H.L.); \\ ndmcyss@mail.ndmctsgh.edu.tw (Y.-S.S.)
} Hsu, C.-C.; Chou, Y.-T.; Shiah, S.-G.; Liu, S.-Y.; Hsieh, A.C.-T.; Yen, C.-Y.; Lee, C.-H.; Shieh, Y.-S. YAP-

Dependent BiP Induction Is Involved in Nicotine-Mediated Oral Cancer Malignancy. Cells 2021, 10, 2080. https://doi.org/10.3390/ cells10082080

Academic Editor: Ritva Tikkanen

Received: 12 July 2021

Accepted: 11 August 2021

Published: 13 August 2021

Publisher's Note: MDPI stays neutral with regard to jurisdictional claims in published maps and institutional affiliations.

Copyright: (c) 2021 by the authors. Licensee MDPI, Basel, Switzerland. This article is an open access article distributed under the terms and conditions of the Creative Commons Attribution (CC BY) license (https:// creativecommons.org/licenses/by/ $4.0 /)$.

\begin{abstract}
Cigarette smoking is a significant risk factor for the development and progression of oral cancer. Previous studies have reported an association between nicotine and malignancy in oral cancer. Recent studies have also demonstrated that nicotine can induce endoplasmic reticulum (ER) stress in tumor cells. Binding immunoglobulin protein (BiP) acts as a master regulator of ER stress and is frequently overexpressed in oral cancer cell lines and tissues. However, the effect of nicotine on BiP in oral cancer is unknown. Therefore, this study aimed to evaluate the role of BiP and its underlying regulatory mechanisms in nicotine-induced oral cancer progression. Our results showed that nicotine significantly induced the expression of BiP in time- and dose-dependent manners in oral squamous cell carcinoma (OSCC) cells. In addition, BiP was involved in nicotine-mediated OSCC malignancy, and depletion of BiP expression remarkably suppressed nicotine-induced malignant behaviors, including epithelial-mesenchymal transition (EMT) change, migration, and invasion. In vivo, BiP silencing abrogated nicotine-induced tumor growth and EMT switch in nude mice. Moreover, nicotine stimulated BiP expression through the activation of the YAP-TEAD transcriptional complex. Mechanistically, we observed that nicotine regulated YAP nuclear translocation and its interaction with TEAD through $\alpha 7$-nAChR-Akt signaling, subsequently resulting in increased TEAD occupancy on the HSPA5 promoter and elevated promoter activity. These observations suggest that $\mathrm{BiP}$ is involved in nicotine-induced oral cancer malignancy and may have therapeutic potential in tobacco-related oral cancer.
\end{abstract}

Keywords: chaperons; cigarette smoking; nicotinic acetylcholine receptors; oncogenes; oral squamous cell carcinoma

\section{Introduction}

Oral cancer is the sixth most common cancer, accounting for $5 \%$ of all cancer cases worldwide [1,2]. Oral squamous cell carcinoma (OSCC) represents over $90 \%$ of all pathological types of oral cancer, and it is a major cause of cancer morbidity and mortality [1]. 
Treatment for oral cancer includes surgical eradication, radiotherapy, chemotherapy, and targeted therapy [3]. Despite advances in diagnosis and therapy, the 5-year survival rate for patients with oral cancer has not significantly improved and remains at $65 \%$ [4]. Therefore, it is important to understand the underlying mechanisms of oral cancer progression. In Southeast Asian countries, oral cancer is a major epidemiological concern due to the habits of betel quid chewing, cigarette smoking, and alcohol drinking [2]. Among them, cigarette smoking is a significant etiological factor associated with the development and progression of oral cancer. More than 7000 components, of which at least 70 are carcinogens, have been identified in tobacco smoke [5]. Previous studies have demonstrated that nicotine, the major addictive constituent of cigarettes, can increase cell proliferation, epithelial-mesenchymal transition (EMT) change, metastasis, and chemoresistance in oral cancer [6-8]. However, the underlying mechanisms involved in nicotine-mediated oral cancer progression are not fully understood.

Recently, several studies have demonstrated nicotine-induced endoplasmic reticulum (ER) stress in both malignant and non-malignant cells, including rat placental trophoblast giant cells, normal lung cells, and lung cancer cells $[9,10]$. Microenvironmental and intracellular stresses including hypoxia, hypoglycemia, acidosis as well as calcium and redox imbalance disturb ER function and may result in the accumulation of misfolded and unfolded proteins, thereby causing ER stress [11]. To overcome ER stress, eukaryotic cells activate homeostatic responses, collectively termed the unfolded protein response (UPR). Increasing evidence has demonstrated that ER stress and UPR components are involved in tumor malignancy $[12,13]$. Binding immunoglobulin protein (BiP) belongs to the heat shock protein 70 (HSP70) family and is composed of a conserved ATPase domain and peptide-binding domain. It is normally expressed at low basal levels in adult organs and is critical for protein folding. However, the hyperexpression of $\mathrm{BiP}$ has been observed in tumor tissues and implicated in tumor proliferation, invasion, metastasis, and resistance to cancer therapies [14-16]. In vitro study has demonstrated higher levels of BiP in oral cancer cell lines compared to normal oral keratinocytes [17]. In addition, tissues from patients with OSCC have also shown remarkably higher expression of BiP compared to normal oral tissues [18]. Interestingly, in HepG2 human hepatoma cells and BeWo human placental trophoblastic cancer cells, nicotine exposure has been reported to increase the expression of BiP $[19,20]$. However, the effect of nicotine on BiP in oral cancer is still unknown.

Nicotine has been demonstrated to have tumorigenic and tumor-promoting activities mainly through the activation of nicotinic acetylcholine receptors (nAChRs) in several types of cancer, including oral cancer [21]. nAChRs are a family of ligand-gated cation channels that are widely expressed in many tissues, including oral epithelial cells [22]. The homopentamer $\alpha 7-\mathrm{nAChR}$, a subtype of $\mathrm{nAChR}$, has been highly associated with proliferation, angiogenesis, and metastasis in cancer [23]. In oral cancer, nicotine has been shown to stimulate cell proliferation and inhibit apoptosis through $\alpha 7-\mathrm{nAChR}[6,7,24,25]$. A recent study showed that $\alpha 7-\mathrm{nAChR}$ signaling was involved in nicotine-regulated UPR activation in rat and human pancreatic $\beta$-cell lines [26]. However, the role of $\alpha 7-\mathrm{nAChR}$ in the regulation of UPR components, especially $\mathrm{BiP}$, upon nicotine exposure in oral cancer is still under investigation.

In the present study, we aimed to investigate the potential role of the ER stressresponsive component, $\mathrm{BiP}$, and its underlying regulatory mechanisms in nicotine-induced oral cancer malignancy. Our results demonstrated that BiP was involved in the promalignant effect of nicotine on oral cancer. In addition, the YAP-TEAD transcriptional complex acted as a downstream effector of the $\alpha 7-\mathrm{nAChR}$-Akt axis in the induction of BiP expression.

\section{Materials and Methods}

\subsection{Cell Line and Cell Culture}

The human OSCC cell lines, OE and SAS, were grown in RPMI medium (GIBCO, Eggenstein, Germany) supplemented with 10\% fetal bovine serum (FBS) (GIBCO, Eggen- 
stein, Germany) and 1\% Penicillin-Streptomycin-Amphotericin B (PSA) (Biological industries, Cromwell, CT, USA). The OE (OECM-1) cells were obtained from Merck Millipore, Darmstadt, Germany. The SAS cells were kindly provided by Dr. Michael Hsiao at Genomics Research Center, Academia Sinica, Taipei, Taiwan.

\subsection{Drugs and Antibodies}

Nicotine (Sigma-Aldrich, St. Louis, MO, USA) was dissolved in ethanol. The primary antibodies used were as follows: BiP (610978), E-cadherin (610182), and ZO-1 (610966) from BD Biosciences, San Jose, CA, USA; fibronectin (ab32419) from Abcam, Cambridge, MA, USA; occludin (\#71-1500) from Thermo Fisher, Pittsburgh, PA, USA; $\alpha 7-n A C h R$ (TA321939) from OriGene, Rockville, MD, USA; phospho-YAP (Ser127) (\#13008), YAP (\#14074), TEAD (\#13295), phospho-Akt (Ser473) (\#9271S), Akt (\#9272S), vimentin (\#5741S) and GAPDH (\#5174S) from Cell signaling, Beverly, MA, USA. Horseradish peroxidase (HRP)-conjugated secondary antibodies were purchased from Jackson ImmunoResearch Laboratories Inc., West Grove, PA, USA.

\subsection{RNA Interference}

siRNAs were synthesized by Dharmacon (Lafayette, CO, USA). The siRNA sequences used for targeting BiP and YAP were 5'-CCACCAAGAUGCUGACAUU- $3^{\prime}$ and $5^{\prime}$-CCACC AAGCUAGAUAAAGA-3', respectively. The siRNA used for targeting $\alpha 7-n A C h R$ was SMARTpool siRNA (a mixture of four individual siRNAs provided as a single reagent). The sequence for non-targeting siRNA was 5'-UAGCGACUAAACACAUCAA-3'. Transfection of siRNA $(20 \mathrm{nM})$ into cells was performed using GenMute siRNA transfection reagent (SignaGen Laboratories, Ijamsville, MD, USA) following the manufacturer's instructions.

\subsection{RNA Extraction and Quantitative Real-Time PCR (RT-PCR)}

Total RNA was extracted using TRIzol reagent (Invitrogen, Carlsbad, CA, USA) and cDNA was generated by reverse transcription of total RNA using a High-Capacity cDNA Synthesis kit (Applied Biosystems, Carlsbad, CA, USA) according to the manufacturer's instructions. RNA was quantified using a NanoDrop Spectrophotometer (NanoDrop, Wilmington, DE, USA). The expressions of related genes in our study were analyzed using quantitative RT-PCR. Quantitative RT-PCR was performed on a Roche LightCycler 480 system with SYBR Green I Master mix (Roche, Indianapolis, IN, USA). The conditions were as follows: an initial heat denaturation at $95^{\circ} \mathrm{C}$ for $2 \mathrm{~min}$, followed by 40 cycles at 95 ${ }^{\circ} \mathrm{C}$ for $5 \mathrm{~s}$ and $60{ }^{\circ} \mathrm{C}$ for $20 \mathrm{~s}$. Glyceraldehyde 3-phosphate dehydrogenase (GAPDH) was used as an internal control. The primer sequences are listed in Table 1.

Table 1. The primer sequences used for quantitative RT-PCR.

\begin{tabular}{ccc}
\hline Gene & $\mathbf{5}^{\prime} \mathbf{- 3}^{\prime}$ & Sequences \\
\hline BiP & Forward & TGA CAT TGA AGA CTT CAA AGC T \\
& Reverse & CTG CTG TAT CCT CTT CAC CAG T \\
$\alpha 7-$-nAchR & Forward & GCT GGT CAA GAA CTA CAA TCC C \\
& Reverse & CTC ATC CAC GTC CAT GAT CTG \\
YAP & Forward & TGA ACA AAC GTC CAG CAA GAT AC \\
& Reverse & CAG CCC CCA AAA TGA ACA GTA G \\
GAPDH & Forward & CCA CAT CGC TCA GAC ACC AT \\
& Reverse & TGA CCA GGC GCC CAA TA \\
\hline
\end{tabular}

\subsection{Scratch Wound Healing Assay}

Cell migration ability was determined using a wound-healing assay. Cells were plated and grown to confluence in six-well plates. The confluent cell monolayer of each well was scratched using a sterile micropipette tip to create a wound. After washing with PBS to remove floating debris, the cells were cultured for an additional $18 \mathrm{~h}$. Closure of the wounded areas was observed using an inverted microscope and photographed at 0 and 
$18 \mathrm{~h}$. ImageJ software was used to quantify the wound area. The migratory ability was calculated by the area reduction at $18 \mathrm{~h}$ compared to the wound area at $0 \mathrm{~h}$.

\subsection{Transwell Invasion Assay}

Cell invasion ability was analyzed using a Transwell assay, which was carried out in 24-well plates using Transwell chambers with an $8-\mu \mathrm{m}$ pore size (Millipore, Billerica, MA, USA) pre-coated with Matrigel (Corning Inc., Corning, NY, USA). Cells were seeded at $2.5 \times 10^{4}$ in the upper chamber of the insert. After $24 \mathrm{~h}$ incubation, the invaded cells on the bottom side of the membrane were fixed with $100 \%$ methanol, stained with propidium iodide (PI), and photographed. The number of invaded cells per microscopic field was determined using ImageJ software.

\subsection{Co-Immunoprecipitation}

Co-immunoprecipitation was performed to analyze interactions between YAP and TEAD proteins. In brief, whole-cell lysates were mixed with the respective antibodies or IgG control overnight at $4{ }^{\circ} \mathrm{C}$. Protein-antibody complexes were incubated with protein $\mathrm{G}$ sepharose beads (GE Healthcare, Piscataway, NJ, USA) on a turning wheel for $4 \mathrm{~h}$ at $4{ }^{\circ} \mathrm{C}$ and immune complexes were washed with PBS and boiled in SDS sample buffer for $10 \mathrm{~min}$. The eluted proteins were subsequently analyzed by Western blot analysis.

\subsection{Chromatin Immunoprecipitation}

Chromatin immunoprecipitation (ChIP) was performed to analyze interactions between the HSPA5 promoter and TEAD protein. The ChIP assay was carried out using a Pierce magnetic ChIP kit (Thermo Fisher, Pittsburgh, PA, USA) according to the manufacturer's protocols. Briefly, cells were cross-linked in 1\% formaldehyde for $10 \mathrm{~min}$, and glycine was added to the cells for $5 \mathrm{~min}$ at room temperature to terminate the cross-linking reaction. Subsequently, chromatin was sheared to fragments by sonication, and the cellular debris was removed by centrifugation. Ten microliters of the cell lysate served as the input control. The remaining samples were divided into two groups followed by incubation with anti-TEAD and non-specific rabbit IgG with rotation at $4{ }^{\circ} \mathrm{C}$ overnight. The immunocomplexes were precleared with protein $\mathrm{A} / \mathrm{G}$ magnetic beads for $2 \mathrm{~h}$ at $4{ }^{\circ} \mathrm{C}$ with mixing. Chromatin was eluted by elution buffer, and crosslinks between protein and DNA were reversed by adding $6 \mu \mathrm{L}$ of $5 \mathrm{M} \mathrm{NaCl}$ and $2 \mu \mathrm{L}$ of $20 \mathrm{mg} / \mathrm{mL}$ Proteinase $\mathrm{K}$ at $65^{\circ} \mathrm{C}$ for $1.5 \mathrm{~h}$. Finally, DNA was recovered using a spin column. Precipitated DNA was used as the template for PCR. The sequences of the PCR primers used for amplifying the HSPA5 promoter region containing the TEAD binding site were as follows: forward $5^{\prime}$-GGCATTATCAAGACGATTTTCGC- $3^{\prime}$ and reverse $5^{\prime}$-GGTTATCATTTACGGGGCTTTC-3'.

\subsection{Luciferase Dual Assay}

Transcriptional activity of the HSPA5 promoter was measured using a luciferase dual assay system. The HSPA5 promoter region containing the TEAD consensus binding motif was amplified by PCR using the designed primers, forward 5'-GGACTAGTCCACGGTAG GCTTTCAG-3' and reverse 5'-CGCGGATCCCTTGCCAGCCAGTTG-3' , and cloned into the pMCS-Cypridina luciferase reporter vector (Thermo Fisher, Pittsburgh, PA, USA). The pTK-Red Firefly luciferase vector (Thermo Fisher, Pittsburgh, PA, USA) was used as an internal control. Polyjet transfection reagent (SignaGen Laboratories, Ijamsville, MD, USA) was used for co-transfection of the two plasmids. Luciferase activity was detected using a luciferase dual assay kit (Thermo Fisher, Pittsburgh, PA, USA) according to the manufacturer's instructions. Firefly luciferase activity (encoded by the control plasmid) was used to normalize Cypridina luciferase activity (encoded by the experimental plasmid).

\subsection{Immunohistochemistry}

Immunohistochemical staining was performed using a Novolink polymer detection system kit (Leica Biosystems Newcastle Ltd., Newcastle, UK) according to the manufac- 
turer's protocols. In brief, formalin-fixed paraffin-embedded tumor sections were deparaffinized in xylene, rehydrated using graded ethanol, and antigen retrieval was performed in Tris-EDTA buffer (pH 9.0) containing $10 \mathrm{mM}$ Tris-base, $1 \mathrm{mM}$ EDTA, and 0.05\% Tween-20. The slides were then incubated with peroxidase block to neutralize endogenous peroxidase and protein block to block non-specific binding, followed by incubation with the respective primary antibodies overnight at $4{ }^{\circ} \mathrm{C}$. Subsequently, the sections were incubated with HRP polymer-conjugated secondary antibodies at room temperature for $1 \mathrm{~h}$. Finally, immunoreactivity was visualized using diaminobenzidine (DAB) chromogen, and the sections were counterstained with hematoxylin, dehydrated, and mounted.

\subsection{Western Blot Analysis}

Protein lysates were extracted by RIPA buffer containing protease (Biological industries, Cromwell, CT, USA) and phosphatase (Biological industries, Cromwell, CT, USA) inhibitors. Nuclear and cytoplasmic fractions were extracted by NE-PER Nuclear and Cytoplasmic Extraction Reagents (Thermo Fisher, Pittsburgh, PA, USA) according to the manufacturer's instructions. Protein concentration was determined using a Pierce BCA protein assay kit (Thermo Fisher, Pittsburgh, PA, USA). Equal amounts of protein samples were electrophoretically separated by sodium dodecyl sulfate polyacrylamide gel electrophoresis (SDS-PAGE) and transferred onto polyvinylidene difluoride (PVDF) membranes (Merck Millipore, Darmstadt, Germany). The membranes were blocked with 5\% non-fat milk for $1 \mathrm{~h}$ at room temperature and then incubated with primary antibodies diluted with blocking buffer overnight at $4{ }^{\circ} \mathrm{C}$. The next day, the membranes were washed with $0.1 \%$ TBST and subsequently incubated with $\mathrm{HRP}$-conjugated secondary antibodies for an additional $1 \mathrm{~h}$ at room temperature. Protein bands were visualized using ECL reagents (Merck Millipore, Darmstadt, Germany) and captured by a chemiluminescence image system (UVP Inc., San Gabriel, CA, USA).

\subsection{Animal Studies}

All animal experiments were performed in accordance with the ethical guidelines approved by the Institutional Animal Care and Use Committee at National Defense Medical Center (NDMC) (Taipei, Taiwan). Male nude mice (4 weeks old) were obtained from the National Laboratory Animal Center (Taipei, Taiwan) and housed in the animal center at NDMC with free access to food and water. SAS cells $\left(1.5 \times 10^{6}\right)$ transfected with scramble shRNA control (SAS-shV) or BiP shRNA (SAS-shBiP) (National RNAi Core Facility, Academia Sinica, Taipei, Taiwan) in PBS mixed with Matrigel at a 1:1 ratio were subcutaneously injected into the right flank of the mice. When the tumor size was about $100 \mathrm{~mm}^{3}$, the mice were randomized into two groups: one group was intraperitoneally administered with PBS, which served as a vehicle control, and the other with nicotine ( $1 \mathrm{mg} / \mathrm{kg}$ body weight daily) $[27,28]$ ( $n=5$ per group). The length and width of tumors were measured every three days with Vernier calipers. The tumor volume was calculated using the following formula: volume $=\left(\right.$ length $\times$ width $\left.^{2}\right) / 2$. At the end of treatment, the mice were sacrificed and the excised tumors were weighed.

\subsection{Statistical Analysis}

The Student's $t$-test was used to determine statistically significant differences between the two groups. For more than two groups, one-way ANOVA followed by Bonferroni's post hoc test was applied. Statistical analysis was performed and graphical representations were obtained using GraphPad Prism software version 5.01 (GraphPad Software Inc., San Diego, CA, USA). Data were represented as the means \pm SEM. A $P$ value less than 0.05 was regarded as being statistically significant. 


\section{Results}

\subsection{Nicotine Remarkably Induced BiP Expression in OSCC Cells}

Nicotine has been reported to be a crucial risk factor for oral cancer development and progression [6-8]. Previous studies have demonstrated that nicotine can induce the expression of $\mathrm{BiP}$ in cancer $[19,20]$. To examine the effect of nicotine on BiP expression, the expression of $\mathrm{BiP}$ in OSCC cells (OE and SAS) treated with various doses (0.1 and $1 \mu \mathrm{M})$ of nicotine for $48 \mathrm{~h}$ or with $1 \mu \mathrm{M}$ nicotine for 6,24 , and $48 \mathrm{~h}$ was analyzed. As shown in Figure 1, protein (Figure 1A,B) and mRNA (Figure 1C,D) expressions of BiP were remarkably increased in a dose- and time-dependent manner after the cells were exposed to nicotine. These results indicated that nicotine could regulate BiP expression in OSCC cells. Since the most obvious change in BiP expression was observed in OSCC cells in response to nicotine at $1 \mu \mathrm{M}$ for $48 \mathrm{~h}$, this dose and timing of nicotine treatment were used in the following experiments.

A
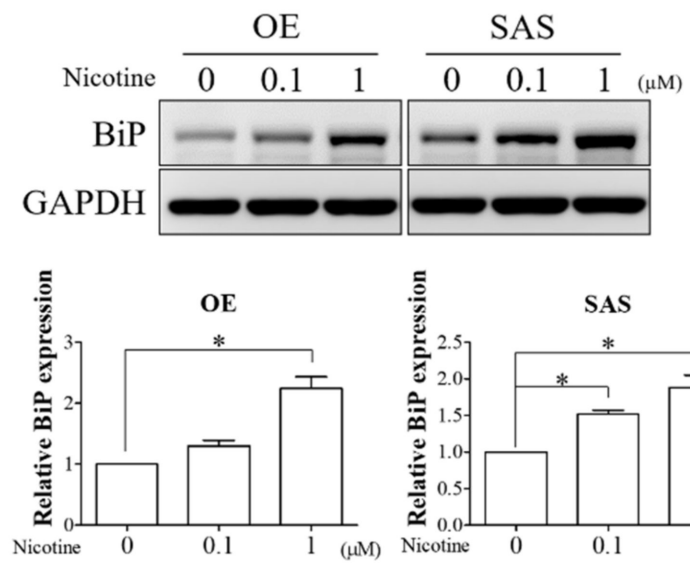

$\mathrm{C}$

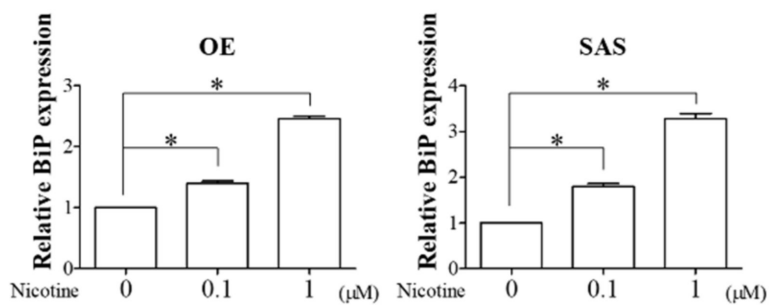

$\mathrm{B}$
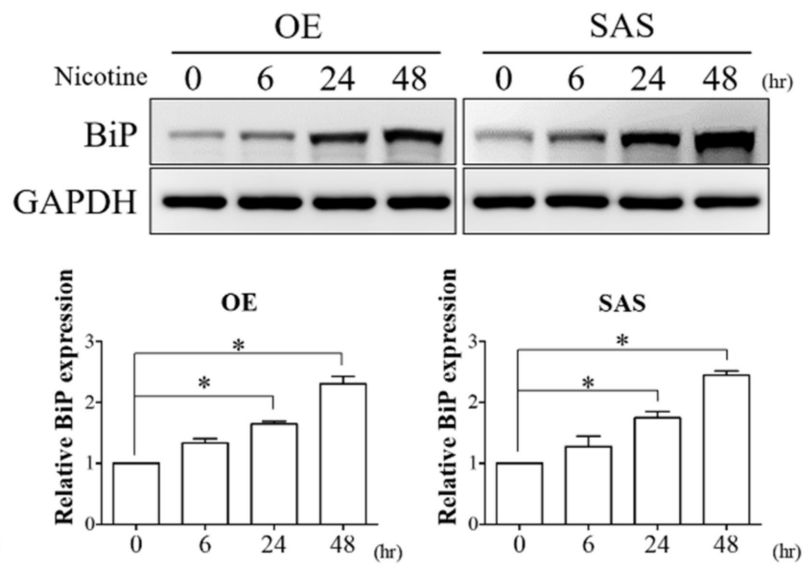

$\mathrm{D}$

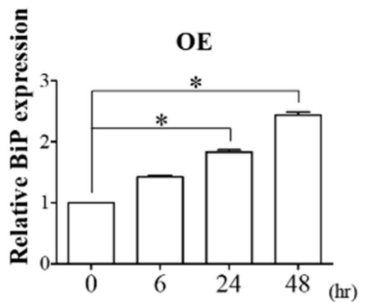

Figure 1. Nicotine increased BiP expression in a dose- and time-dependent manner. $(A, C)$ OE and SAS cells were treated with 0.1 and $1 \mu \mathrm{M}$ of nicotine for $48 \mathrm{~h}$. The dose-dependent effect of nicotine on BiP expression was analyzed by Western blot analysis and quantitative RT-PCR. The graphs show the quantification of Western blots (A, lower panels). Band intensities were quantified using ImageJ software. The relative protein expression of BiP was normalized to GAPDH expression. (B,D) OE and SAS cells treated with $1 \mu \mathrm{M}$ nicotine for 6, 24, and $48 \mathrm{~h}$ were subjected to Western blot analysis and quantitative RT-PCR for investigating the time-dependent effect of nicotine on the expression of BiP. The graphs demonstrate the quantification of Western blots (B, lower panels). Band intensities were analyzed using ImageJ software. The relative protein expression of BiP was normalized to GAPDH expression. GAPDH was used as the loading control. ${ }^{*} p<0.05$ by one-way ANOVA followed by Bonferroni's post hoc test. Data are presented as the mean \pm SEM of three independent experiments. SEM, error bars.

\subsection{BiP Was Involved in Nicotine-Stimulated Malignant Behaviors in OSCC Cells}

The overexpression of BiP has been reported to be involved in mediating tumorigenic functions such as EMT change, migration, and invasion [29]. To explore the potential involvement of $\mathrm{BiP}$ in nicotine-mediated OSCC progression, OSCC cells with/without 
knockdown of BiP expression were exposed to nicotine, and the expressions of epithelial (Ecadherin and ZO-1) and mesenchymal (vimentin and fibronectin) markers and migratory and invasive abilities were subsequently analyzed. We observed that nicotine treatment remarkably increased BiP expression and EMT change, as demonstrated by the decreased expressions of epithelial markers (E-cadherin and ZO-1) and increased expressions of mesenchymal markers (vimentin and fibronectin), in OSCC cells (Figure 2A-C). Migration (Figure 2D) and invasion (Figure 2E) were also increased in nicotine-treated OSCC cells. Furthermore, these effects were significantly suppressed in BiP-silenced cells. These results indicated the oncogenic role of BiP in nicotine-mediated OSCC malignant behaviors.

A
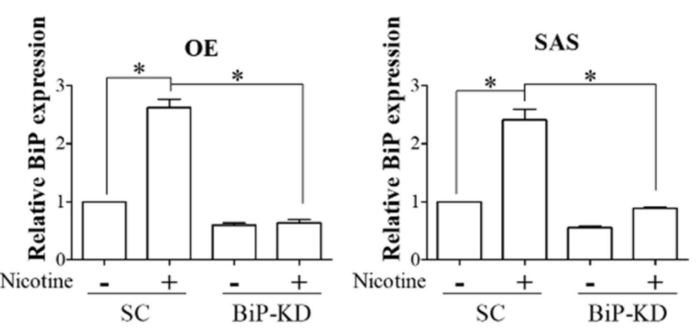

C
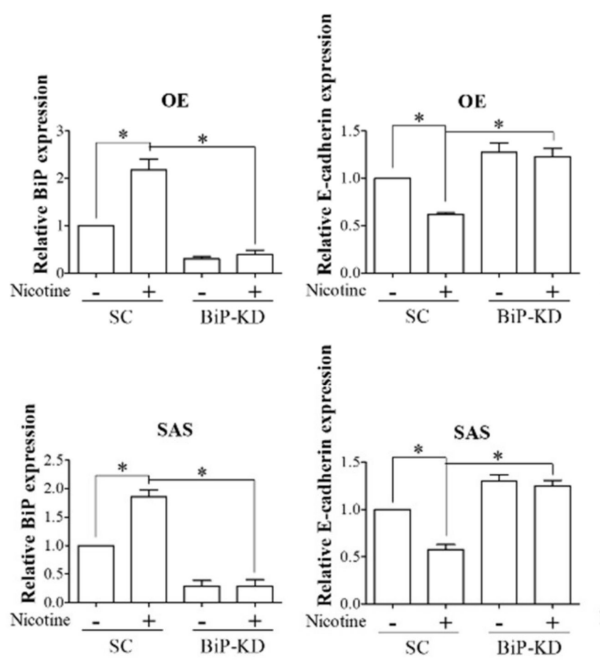

B
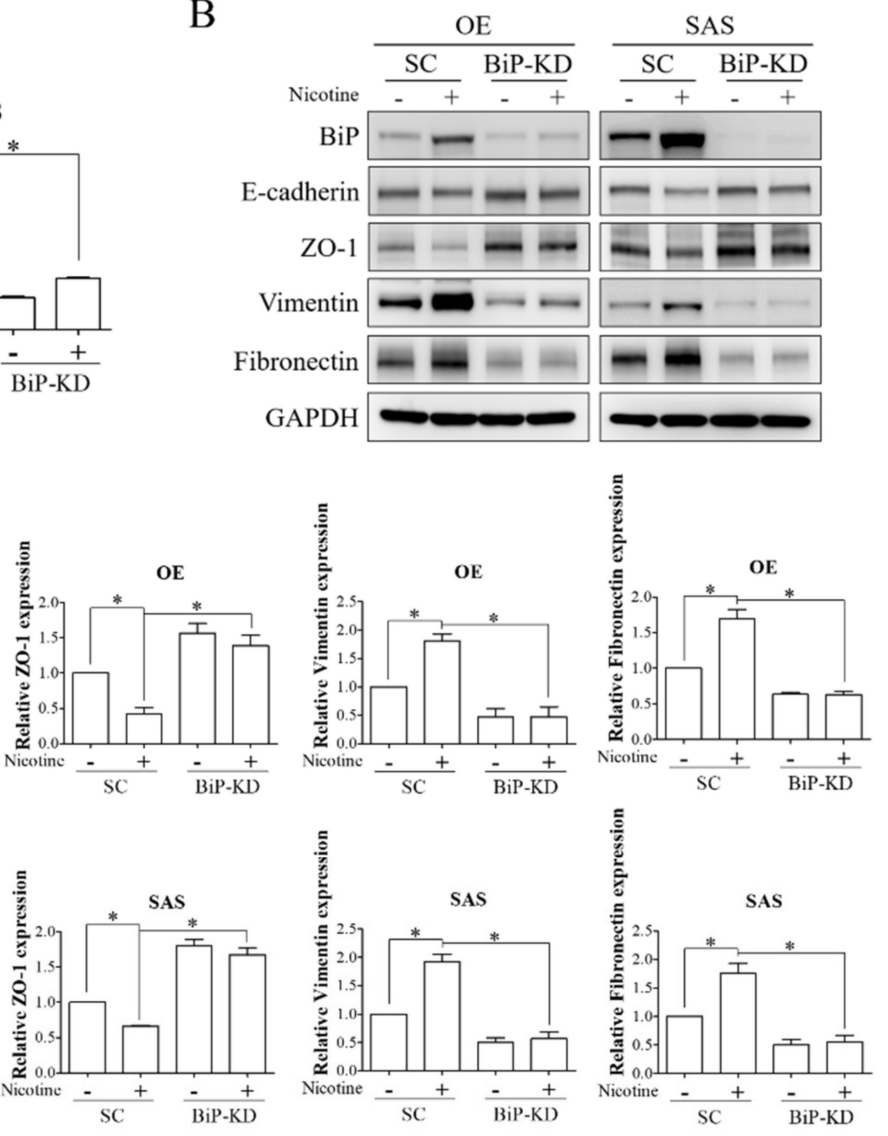

D

E
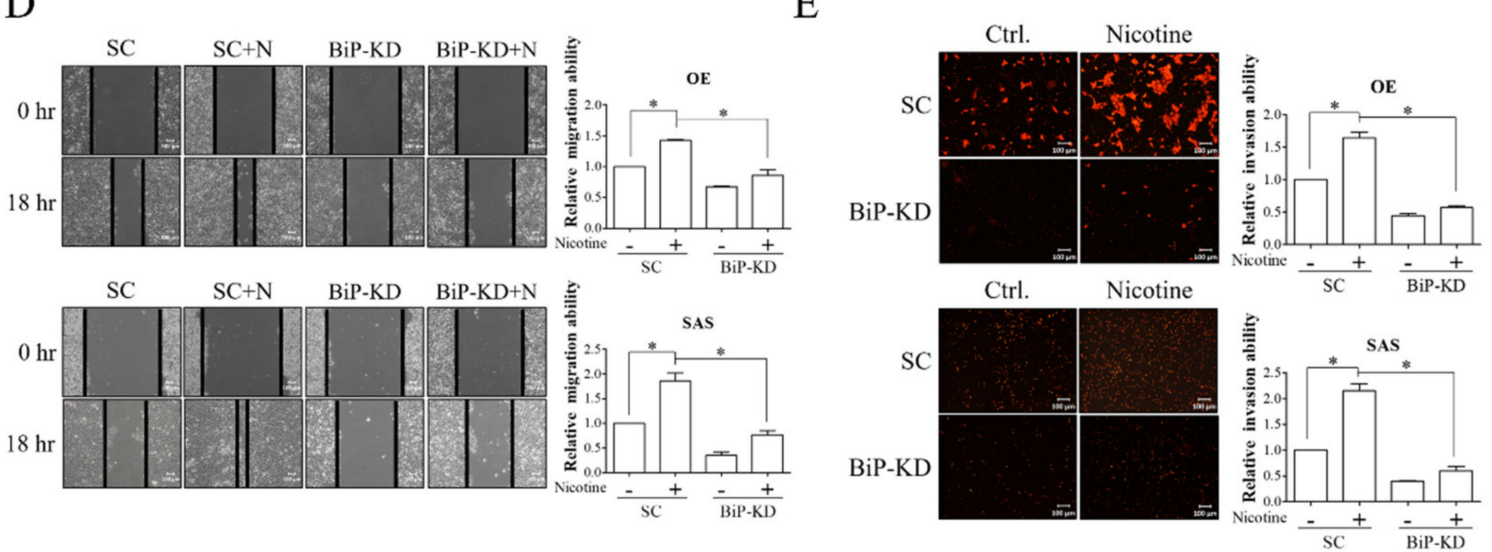

Figure 2. BiP was involved in the pro-malignant effect of nicotine on EMT, migration, and invasion in OSCC. OE and SAS cells were transfected with either non-targeting siRNA or BiP siRNA followed by $1 \mu \mathrm{M}$ nicotine exposure for $48 \mathrm{~h}$. (A) The 
expression of BiP was examined using quantitative RT-PCR. (B) The expressions of BiP, epithelial (E-cadherin and ZO-1), and mesenchymal (vimentin and fibronectin) markers in OSCC cells after the indicated treatments were analyzed by Western blot analysis. (C) The graphs show the quantification of Western blots. Band intensities were quantified using ImageJ software. The relative expressions of BiP, E-cadherin, ZO-1, vimentin, and fibronectin were normalized to GAPDH expression. (D) The ability of cell migration was investigated by wound-healing assay. Representative images were acquired, and black solid lines indicate the wound borders at 0 and $18 \mathrm{~h}$ post-scratching (D, left panels). The quantitative results of wound closure were determined using ImageJ software (D, right panels). The ability of migration was calculated by the area reduction at $18 \mathrm{~h}$ compared to the wound area at $0 \mathrm{~h}$. (E) The invasive ability was determined by Transwell chambers pre-coated with Matrigel. Cells that penetrated across the membrane were fixed with methanol and stained with propidium iodide (PI). The quantitative results of PI-stained invasive cells were analyzed using ImageJ software (E, right panels). N, nicotine. SC, non-targeting siRNA-transfected cells. BiP-KD, BiP siRNA-transfected cells. GAPDH was used as the loading control. ${ }^{*} p<0.05$ by one-way ANOVA followed by Bonferroni's post hoc test. Data are presented as the mean \pm SEM of three independent experiments. SEM, error bars. Scale bar, $100 \mu \mathrm{m}$.

\subsection{Nicotine Induced BiP Expression and Tumor Progression via $\alpha 7-n A C h R-A k t$ Signaling in OSCC Cells}

Nicotine has been reported to promote cancer progression mainly through the acti-

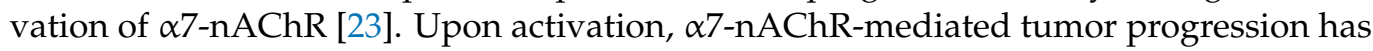
been partly attributed to the phosphoinositide 3-kinase (PI3K)/Akt signaling pathway [30]. To investigate the involvement of $\alpha 7-\mathrm{nAChR}$ signaling in mediating the effect of nicotine on BiP expression and malignant behaviors in OSCC, OSCC cells transfected with non-targeting siRNA or $\alpha 7$-nAChR siRNA were exposed to nicotine. The expression of $\alpha 7-n A C h R$ was significantly increased after nicotine treatment in scramble-transfected cells, and this effect was suppressed in $\alpha 7-n A C h R$-silenced cells (Figure $3 \mathrm{~A}-\mathrm{C}$ ). In addition, the stimulatory effects of nicotine on the expressions of phosphorylated Akt at serine 473 and BiP were diminished by knockdown of $\alpha 7-n A C h R$ expression (Figure $3 \mathrm{~A}-\mathrm{C}$ ). Wound-healing migration and Transwell invasion assays showed that nicotine-induced migration and invasion were abrogated in $\alpha 7-\mathrm{nAChR}$-silenced cells (Figure 3D,E). These findings indicated that $\alpha 7-\mathrm{nAChR}$ acted as a crucial regulator of nicotine and its effects on BiP expression and malignant behaviors in OSCC.

\subsection{The YAP-TEAD Transcriptional Complex Was the Downstream Effector of $\alpha 7-n A C h R-A k t$} Signaling in Nicotine-Induced BiP Expression and Malignant Behaviors

YAP transcriptional cofactor has been reported to be a potential driver of OSCC progression [31]. YAP is predominantly associated with the TEAD transcription factor to drive the transactivation of downstream target genes [32]. Regulation of YAP-TEAD transcriptional activity primarily depends on phosphorylation-dependent YAP nucleocytoplasmic shuttling [32]. When phosphorylated by upstream kinases, YAP is localized in the cytoplasm and is unable to interact with TEAD. In contrast, upon dephosphorylation, YAP can translocate into the nucleus and form a complex with TEAD. In addition, a previous study has demonstrated that nicotine can induce nuclear localization and activation of YAP [33]. Hence, to evaluate the potential role of the YAP-TEAD complex as a downstream regulator of the $\alpha 7-n A C h R-A k t$ pathway in nicotine-induced BiP expression, OSCC cells with/without depletion of $\alpha 7-\mathrm{nAChR}$ expression were treated with nicotine, and the phosphorylation status of YAP was subsequently detected. Nicotine exposure resulted in dephosphorylation of YAP in OSCC cells, as evidenced by a decreased level of phosphorylated YAP at serine 127, and the effect of nicotine on YAP dephosphorylation was diminished in $\alpha 7-n A C h R$-silenced cells (Figure 4A,B). Since YAP dephosphorylation leads to its nuclear accumulation, the role of $\alpha 7-\mathrm{nAChR}$ in the subcellular distribution of YAP after nicotine treatment in OSCC cells was evaluated. Increased nuclear translocation of YAP was observed in the cells treated with nicotine, and this was suppressed by silencing $\alpha 7-n A C h R$ expression (Figure 4C). Furthermore, we observed that nicotine treatment resulted in increased interaction between YAP and TEAD, but that this interaction was decreased in $\alpha 7$-nAChR-knockdown OSCC cells after nicotine exposure (Figure 4D). These 
findings indicated that $\alpha 7-\mathrm{nAChR}$ signaling was the crucial regulator of nicotine-induced YAP nuclear distribution and activation.

A
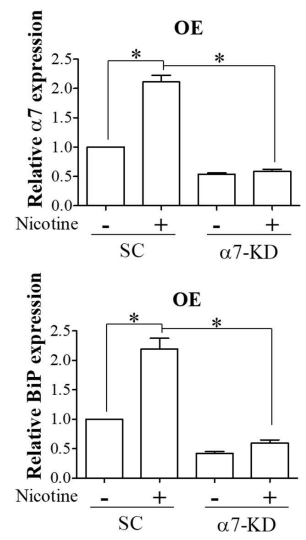

$\mathrm{C}$
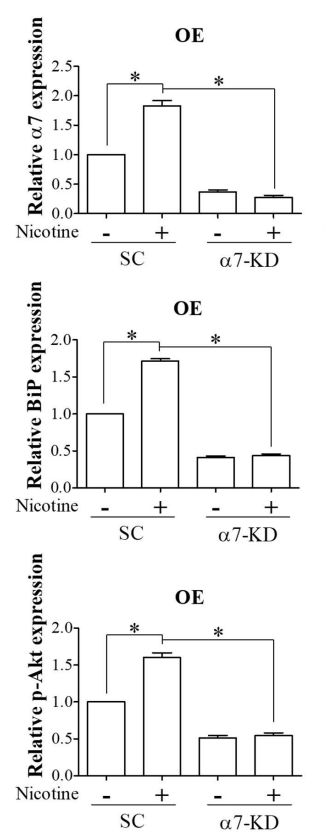
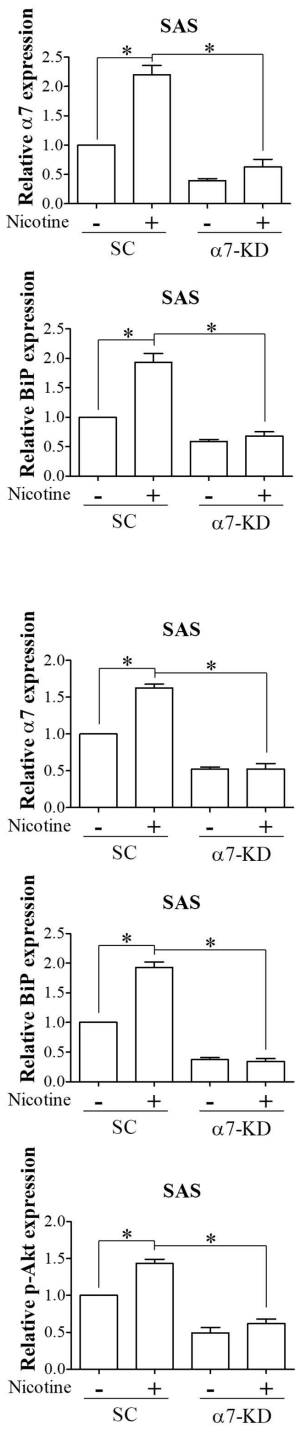

B

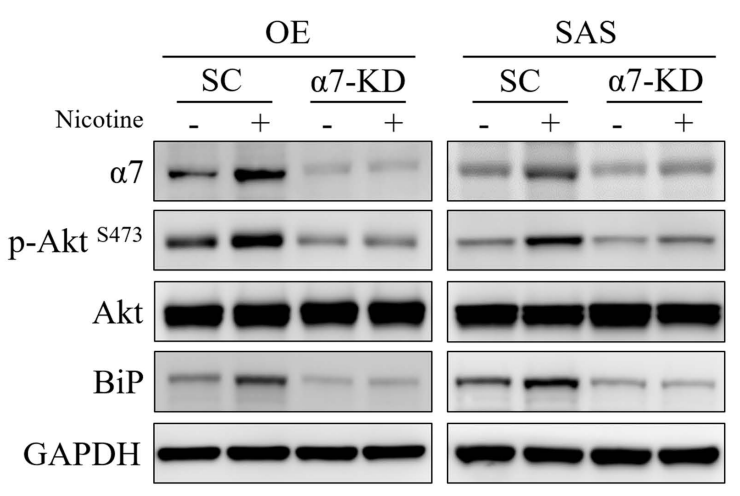

$\mathrm{D}$
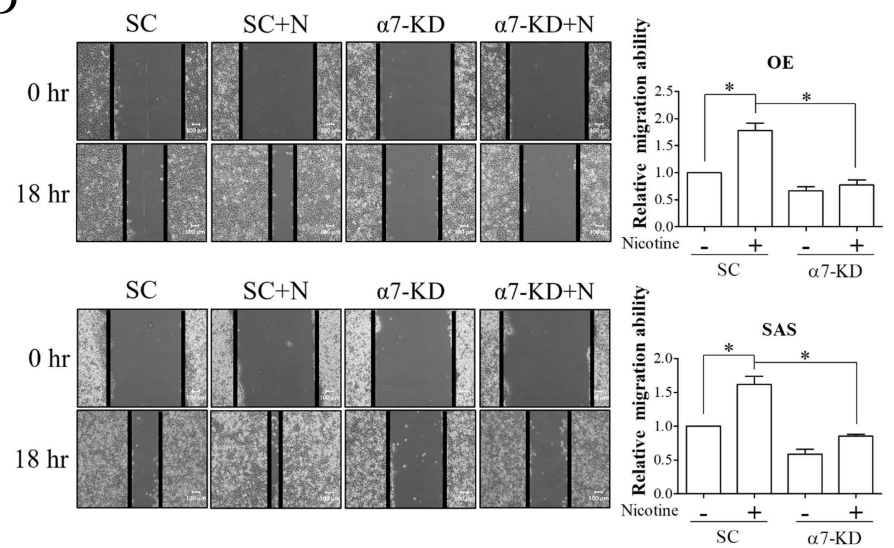

$\mathrm{E}$

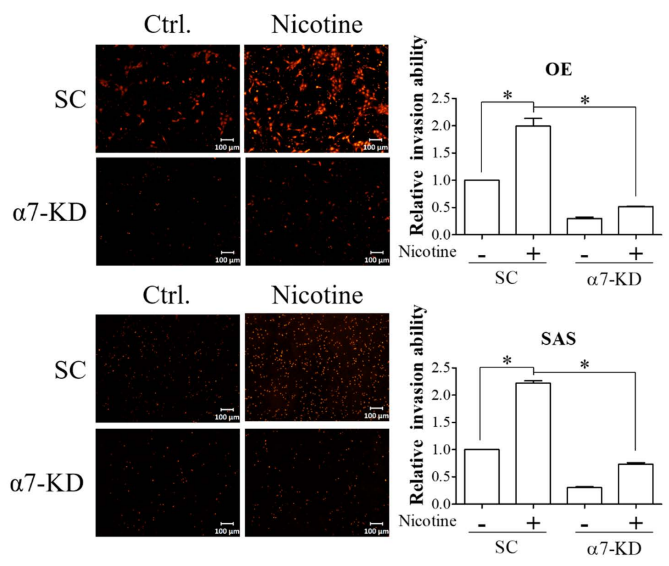

Figure 3. $\alpha 7-n A C h R-A k t$ signaling was involved in nicotine-induced BiP expression and malignant behaviors in OSCC. $\mathrm{OE}$ and SAS cells with/without $\alpha 7$-nAChR silencing were treated with $1 \mu \mathrm{M}$ nicotine for $48 \mathrm{~h}$. (A,B) The expressions of $\alpha 7-n A C h R$ and BiP and activation of Akt, as indicated by the expression level of phospho-Akt at Ser473, were analyzed by quantitative RT-PCR and Western blot analysis. (C) The graphs show the quantification of Western blots. Band intensities were quantified using ImageJ software. The relative protein expressions of $\alpha 7-\mathrm{nAChR}$ and BiP were normalized to GAPDH expression. The relative protein expression of phospho-Akt (Ser473) was normalized to total Akt expression. The migratory (D) and invasive (E) abilities were examined by wound healing and Transwell invasion assays. Representative images are 
shown, and black solid lines indicate the wound borders acquired at 0 and $18 \mathrm{~h}$ after scratching (D, left panels). Quantitative results of migratory cells (D, right panels) and PI-stained invasive cells (E, right panels) were determined using ImageJ software. The ability of migration was calculated by the area reduction at $18 \mathrm{~h}$ compared to the wound area at $0 \mathrm{~h}$. $\mathrm{N}$, nicotine. SC, non-targeting siRNA-transfected cells. $\alpha 7-\mathrm{KD}, \alpha 7-n A C h R$ siRNA-transfected cells. GAPDH was used as the loading control. ${ }^{*} p<0.05$ by one-way ANOVA followed by Bonferroni's post hoc test. Data are presented as the mean \pm SEM of three independent experiments. SEM, error bars. Scale bar, $100 \mu \mathrm{m}$.

A

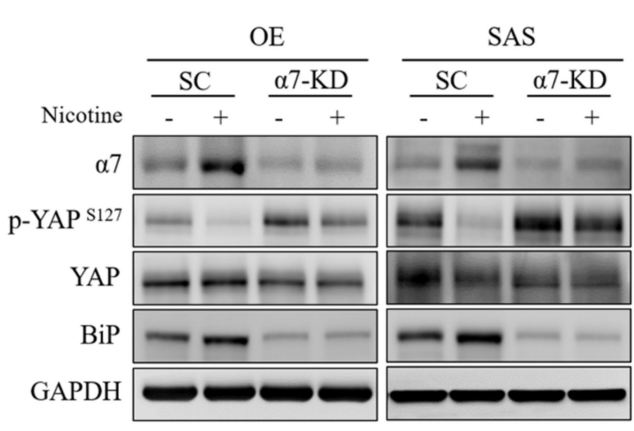

C
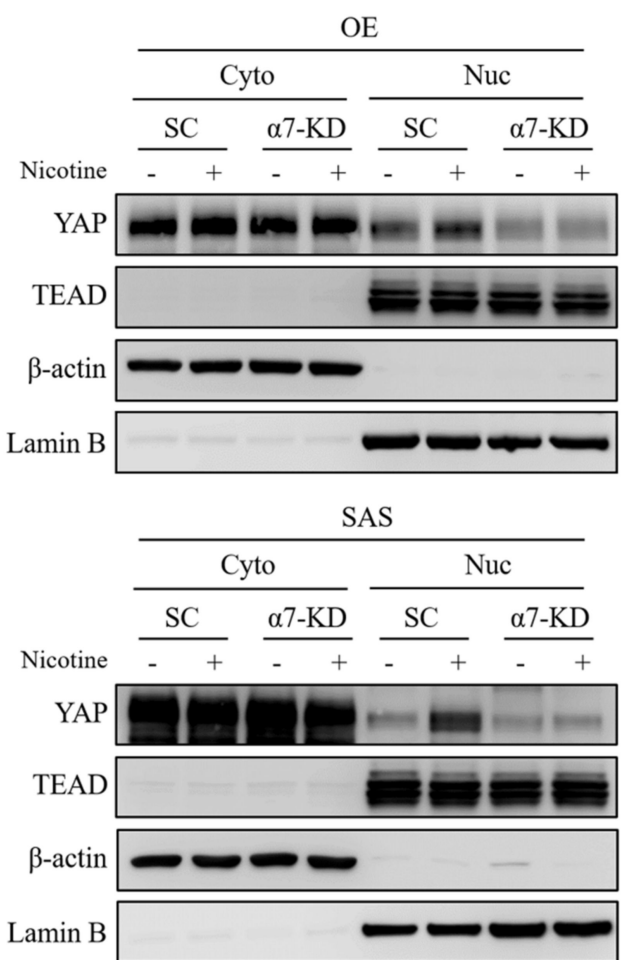

E

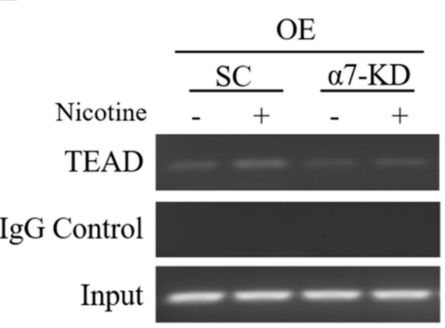

B
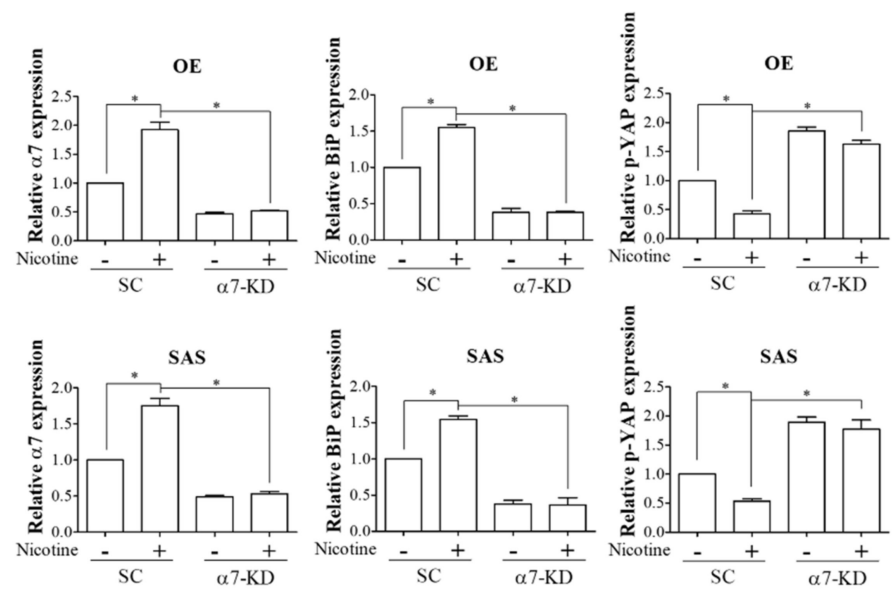

D
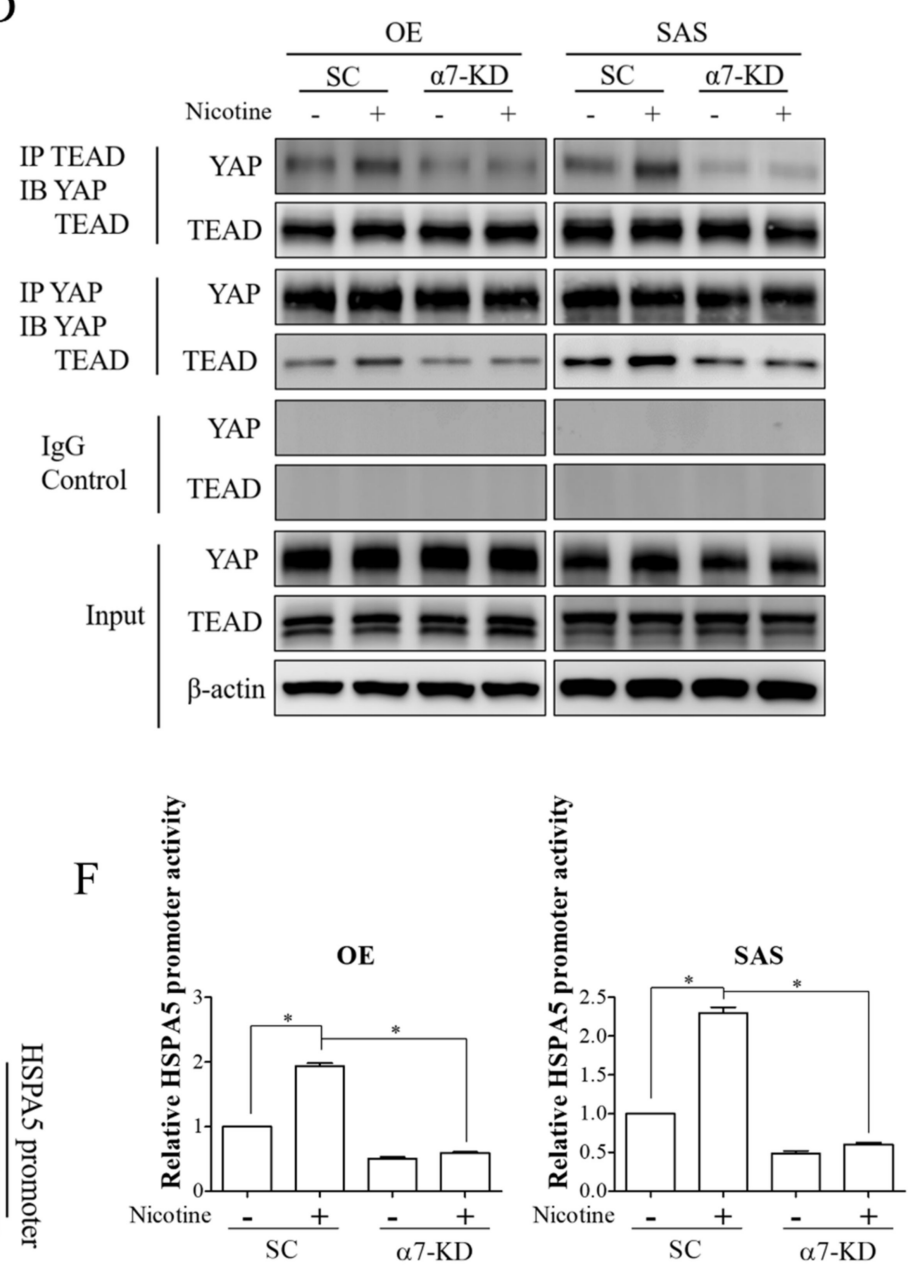

Figure 4. $\alpha 7$-nAChR-Akt signaling increased YAP activation, DNA binding, and transactivation abilities of the YAP-TEAD complex upon nicotine exposure. OE and SAS cells transfected with either non-targeting siRNA or $\alpha 7$-nAChR siRNA were 
treated with $1 \mu \mathrm{M}$ nicotine for $48 \mathrm{~h}$. (A) The expressions of $\alpha 7-\mathrm{nAChR}$, phospho-YAP (Ser127), YAP, and BiP were assessed by Western blot analysis. (B) The graphs show the quantification of Western blots. Band intensities were quantified using ImageJ software. The relative expressions of $\alpha 7-n A C h R$ and BiP were normalized to GAPDH expression. The relative expression of phospho-YAP (Ser127) was normalized to total YAP expression. (C) Subcellular localization of YAP and TEAD were detected by investigating the expression levels of these molecules in the cytoplasmic and nuclear fractions. The cytoplasmic and nuclear extracts were obtained by NE-PER nuclear and cytoplasmic extraction reagents and investigated for YAP and TEAD expressions by Western blot analysis. $\beta$-actin and Lamin B were used as loading controls for the cytoplasmic and nuclear extracts, respectively. (D) The interaction of YAP with TEAD was evaluated by co-immunoprecipitation analysis. Western blot analysis of YAP and TEAD was performed after immunoprecipitation with anti-YAP, anti-TEAD, or anti-rabbit IgG antibodies. (E) Occupancy of TEAD on the HSPA5 promoter was analyzed by chromatin immunoprecipitation assay. Sheared chromatin was immunoprecipitated with anti-TEAD or anti-rabbit IgG antibodies followed by capture with protein agarose beads. The eluted chromatin was subjected to PCR amplification to detect DNA fragments of the HSPA5 promoter region containing the TEAD binding site. (F) The promoter activity of HSPA5 was examined by luciferase reporter assay. $\alpha 7$-nAChR-silenced OE and SAS cells were co-transfected with Cypridina luciferase reporter plasmids constructed with the HSPA5 promoter containing the TEAD binding site and red firefly luciferase plasmids, followed by treatment with $1 \mu \mathrm{M}$ nicotine for $48 \mathrm{~h}$. Luciferase activity was detected using a luciferase dual assay system. Firefly luciferase activity was used to normalize Cypridina luciferase activity. SC, non-targeting siRNA-transfected cells. $\alpha 7-\mathrm{KD}, \alpha 7-\mathrm{nAChR}$ siRNA-transfected cells. GAPDH and $\beta$-actin served as the loading controls. Rabbit IgG was used as a negative control. ${ }^{*} p<0.05$ by one-way ANOVA followed by Bonferroni's post hoc test. Data are presented as the mean \pm SEM of three independent experiments. SEM, error bars.

The TEAD protein has been shown to have an N-terminal DNA binding domain which is responsible for recognizing the sequence motif 5'-GGAATG-3' [34]. We observed one putative TEAD binding site located within the promoter region of HSPA5, which was the gene that encoded BiP. Therefore, we investigated the association between TEAD and the HSPA5 promoter. We observed that the occupancy of TEAD on the HSPA5 promoter was remarkably increased in nicotine-treated cells. Moreover, this binding was disrupted by knockdown of $\alpha 7-n A C h R$ expression (Figure 4E). Owing to the stronger association between TEAD and the HSPA5 promoter region after nicotine treatment, we examined the promoter activity of HSPA5. Nicotine treatment markedly led to elevated promoter activity of HSPA5, and this was decreased by silencing $\alpha 7$-nAChR expression (Figure $4 \mathrm{~F}$ ). These results indicated that nicotine modulated the DNA binding and transactivation abilities of the YAP-TEAD complex through $\alpha 7$-nAChR signaling in OSCC.

We subsequently investigated whether the YAP-TEAD complex was a downstream effector of $\alpha 7$-nAChR signaling in nicotine-induced BiP expression by knockdown of YAP expression. The mRNA and protein expressions of YAP were significantly decreased in $\mathrm{OE}$ and SAS cells transfected with YAP siRNA compared to those with non-targeting siRNA (Figure 5A-C). The effect of nicotine on the induction of BiP expression was abolished by knockdown of YAP expression (Figure 5A-C). Using wound-healing migration and Transwell invasion assays, we demonstrated that YAP silencing resulted in decreased nicotineinduced migration and invasion in OSCC cells (Figure 5D,E). These results indicated that the YAP-TEAD transcriptional complex was a downstream regulator of $\alpha 7-\mathrm{nAChR}$ signaling in nicotine-stimulated BiP expression and tumor malignancy. 
A
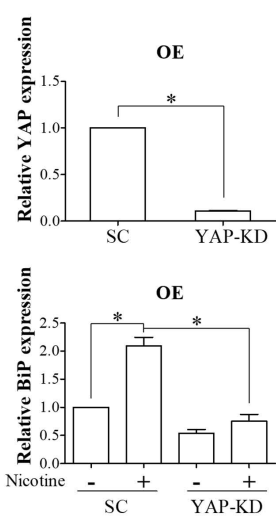

$\mathrm{C}$
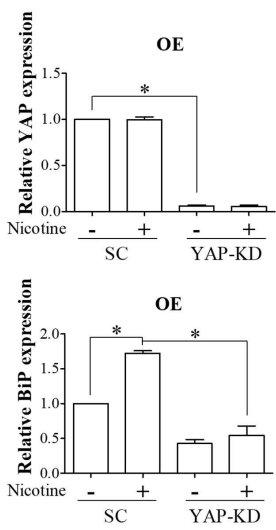
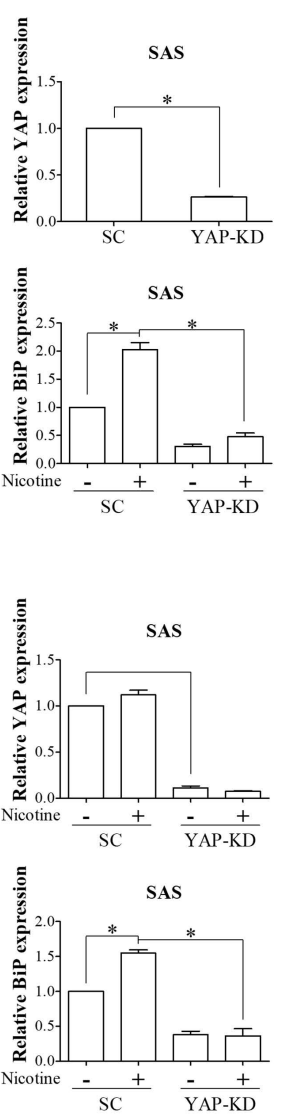

$\mathrm{B}$

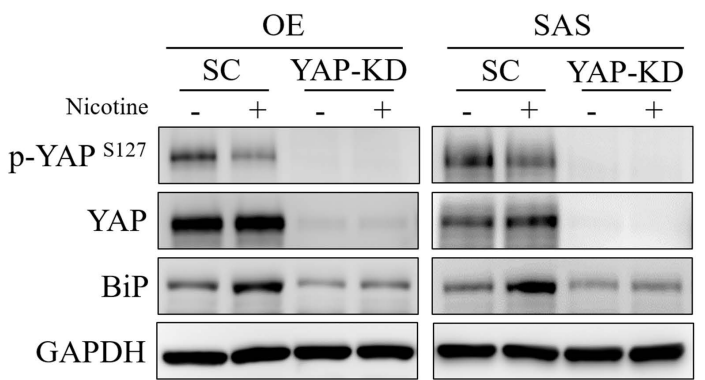

$\mathrm{D}$
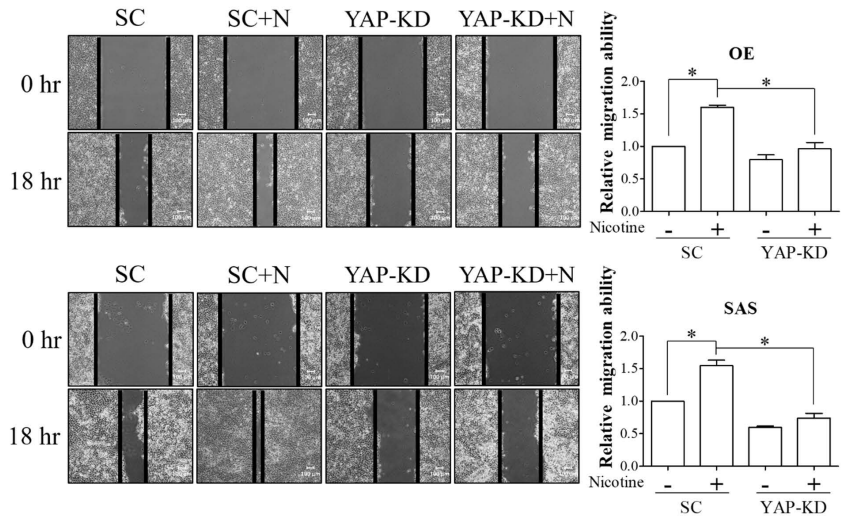

$\mathrm{E}$

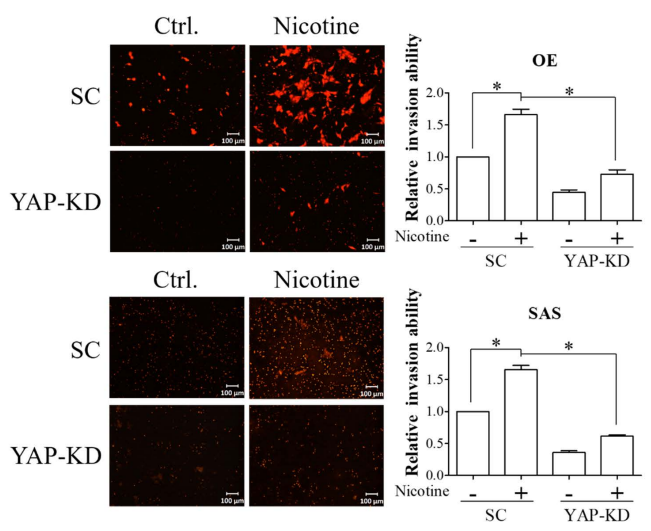

Figure 5. The YAP-TEAD transcriptional complex was involved in the regulation of nicotine-induced BiP expression and tumor malignancy in OSCC. OE and SAS cells transfected with non-targeting siRNA or YAP siRNA were exposed to $1 \mu \mathrm{M}$ nicotine for $48 \mathrm{~h}$. (A,B) The expressions of phospho-YAP (Ser127), YAP, and BiP were analyzed by quantitative RT-PCR and Western blot analysis. (C) The graphs show the quantification of Western blots. Band intensities were quantified using ImageJ software. The relative protein expressions of BiP and YAP were normalized to GAPDH expression. The abilities of cell migration (D) and invasion (E) were investigated using wound-healing and Transwell invasion assays, respectively. Black solid lines on the acquired images indicate the wound borders at 0 and $18 \mathrm{~h}$ post-scratching (D, left panels). Quantitative results of migratory cells across the wound borders (D, right panels) and PI-stained invasive cells (E, right panels) were determined using ImageJ software. The migratory ability was calculated by the area reduction at $18 \mathrm{~h}$ compared to the wound area at $0 \mathrm{~h}$. $N$, nicotine. SC, non-targeting siRNA-transfected cells. YAP-KD, YAP siRNA-transfected cells. GAPDH served as the loading control. * $p<0.05$ by Student's $t$-test or one-way ANOVA followed by Bonferroni's post hoc test. Data are presented as the mean \pm SEM of three independent experiments. SEM, error bars. Scale bar, $100 \mu \mathrm{m}$. 


\subsection{BiP Silencing Decreased Nicotine-Induced Cell Growth and EMT in Tumor-Bearing Mice}

To further validate the involvement of $\mathrm{BiP}$ in nicotine-induced OSCC progression, nude mice subcutaneously implanted with SAS-shV or SAS-shBiP cells were subjected to PBS or nicotine treatment. Tumor growth and size were remarkably increased in the nicotine-treated group compared with the PBS-treated group, whereas BiP silencing inhibited nicotine-induced cell growth (Figure 6A-C). Body weight loss was not observed in all treatment groups (Figure 6D). Furthermore, immunohistochemical results showed increased expressions of BiP and mesenchymal markers (fibronectin and vimentin) and decreased expressions of epithelial markers (occludin and E-cadherin) in tumors from the mice treated with nicotine (Figure 6E). Moreover, the effect of nicotine on EMT change was suppressed by BiP inhibition (Figure $6 \mathrm{E}$ ). These results further indicated the pro-tumor role of BiP in nicotine-mediated OSCC malignancy in mice.

A

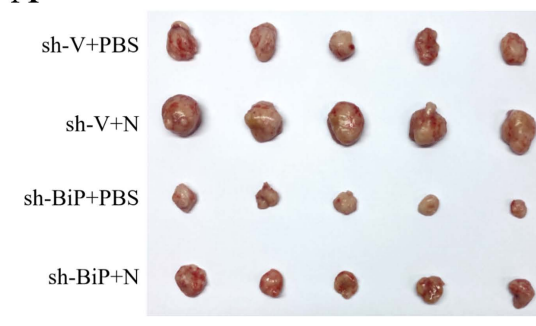

$\mathrm{C}$

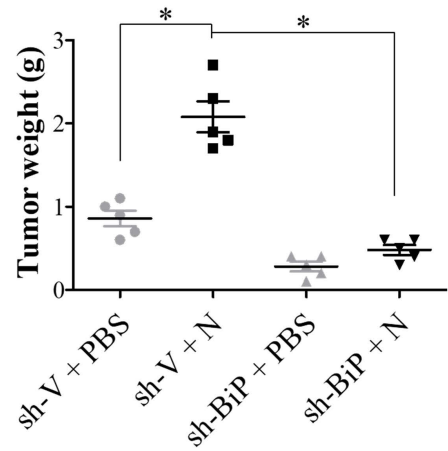

$\mathrm{B}$

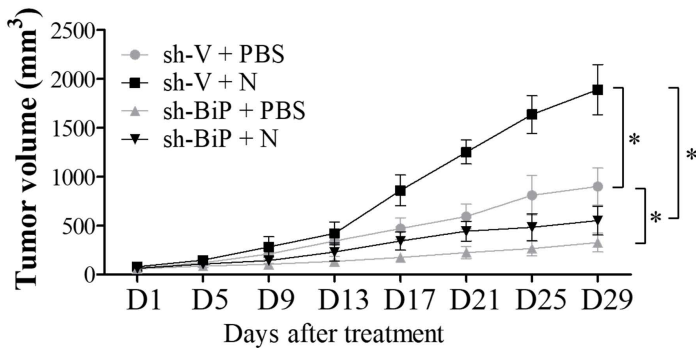

$\mathrm{D}$

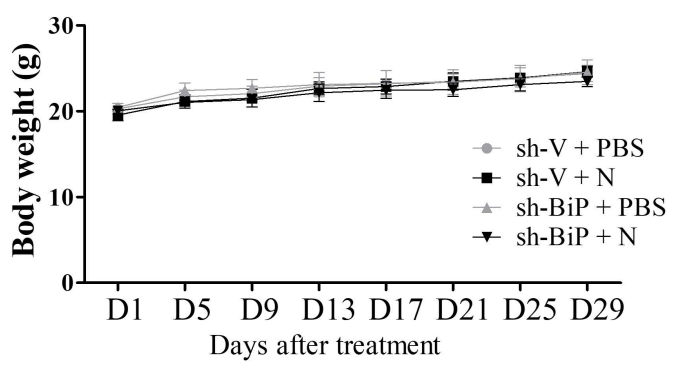

$\mathrm{E}$

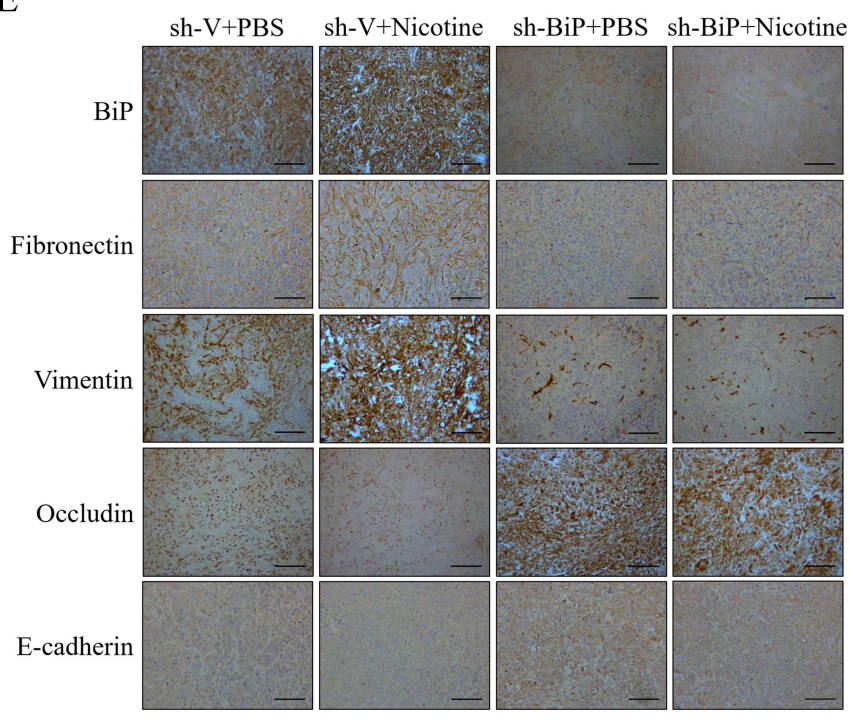

Figure 6. BiP inhibition suppressed nicotine-induced oral cancer progression in nude mice. SAS cells transfected with scramble shRNA control (SAS-shV) or BiP shRNA (SAS-shBiP) $\left(1.5 \times 10^{6}\right.$ cells $/$ mice) were subcutaneously implanted 
into the right flank of nude mice. When the tumor size was about $100 \mathrm{~mm}^{3}$, the tumor-bearing mice were given daily intraperitoneal injections of either PBS or $1 \mathrm{mg} / \mathrm{kg}$ nicotine for one month. Following treatment, the mice were sacrificed and the tumor tissues were subjected to immunohistochemical staining for BiP and epithelial-mesenchymal transition (EMT) markers. (A) Representative images of dissected tumors $(n=5)$ from the nude mice. Average tumor growth curve (B) and tumor weight $(\mathbf{C})$ in each group of mice $(n=5)$ were also recorded during treatment and at the time of mice sacrifice, respectively. The xenograft tumor volumes were measured twice every week using Vernier calipers and calculated using the formula: volume $=\left(\right.$ length $\left.\times w_{i d t h}^{2}\right) / 2$. (D) The average body weight change of the nude mice. Bodyweight was measured twice every week. (E) Representative immunohistochemical staining images of the expressions of BiP, mesenchymal (fibronectin and vimentin), and epithelial (occludin and E-cadherin) markers in tumor tissues. $\mathrm{N}$, nicotine. ${ }^{*} p<0.05$ by one-way ANOVA followed by Bonferroni's post hoc test. Data are presented as the mean \pm SEM of 5 mice in each group. SEM, error bars. Scale bar, $100 \mu \mathrm{m}$.

\section{Discussion}

Cigarette smoking is highly associated with the development of oral cancer, accounting for $75 \%$ of all oral cancer cases [35]. Nicotine is an important component in cigarette smoking, and it has been reported to cause the malignant behaviors of OSCC [6-8]; however, the molecular mechanisms underlying these effects have not been fully elucidated. In particular, the effect of nicotine on the ER stress-responsive protein, BiP, has not been reported in OSCC. Our study demonstrated that BiP was involved in nicotine-induced OSCC progression. Notably, the underlying mechanisms of nicotine-induced BiP expression were through $\alpha 7$-nAChR-Akt signaling and the subsequent activation of the YAP-TEAD transcriptional complex.

In this study, we found that $\alpha 7-n A C h R$ participated in the nicotine-induced expression of BiP. Homomeric $\alpha 7-\mathrm{nAChR}$ is ubiquitously expressed in mammalian cells and is regarded to be the principal receptor involved in nicotine-mediated cancer progression [36]. Our results showed that $\alpha 7-\mathrm{nAChR}$ expression was upregulated in OSCC cells in response to nicotine treatment. Consistently, an increased expression of $\alpha 7-\mathrm{nAChR}$ has been observed in normal human bronchial epithelial cells (NHBE) upon nicotine exposure [37]. Schaal et al. reported that nicotine could induce the expression of $\alpha 7-\mathrm{nAChR}$ through the activation of $\alpha 7-n A C h R$ signaling [38]. Moreover, they reported that the treatment of A549 non-small cell lung adenocarcinoma cells with $\alpha$-bungarotoxin ( $\alpha$-BTX), an inhibitor of $\alpha 7-n A C h R$, abrogated the nicotine-mediated induction of $\alpha 7-n A C h R$ [38]. These results indicate the existence of an autoregulatory feed-forward loop in nicotine-induced $\alpha 7-\mathrm{nAChR}$ upregulation, which can further amplify the downstream signals mediated by nicotine. Hence, it has been suggested that antagonists of $\alpha 7-n A C h R$ may have anti-tumor effects against tobacco-related cancers [39,40]. For example, Dinicola et al. reported the effect of nicotine on interfering with the cytotoxicity of chemotherapeutics was suppressed by exposure to $\alpha$-BTX [39]. Furthermore, genetic or pharmacological blockade of $\alpha 7-\mathrm{nAChR}$ has been shown to abolish nicotine-induced tumor growth in non-small cell lung cancer [40]. In the present study, we showed that nicotine could increase the expression of the ER stress-responsive protein, $\mathrm{BiP}$, through $\alpha 7-\mathrm{nAChR}$ signaling. The controversial link between $\mathrm{nAChR}$ signaling and UPR components has been previously reported in non-tumor cells [26,41]. For example, Srinivasan et al. showed that pharmacological chaperoning of $\mathrm{nAChR}$ after nicotine treatment could repress ER stress and UPR activation, which in turn resulted in neuroprotection of Neuro-2a cells [41]. In addition, Ishibashi et al. observed that nicotine suppressed ER stress-induced apoptosis in pancreatic $\beta$-cells by regulating UPR activation through $\alpha 7-n A C h R$ [26]. The detailed mechanisms contributing to this discrepancy have not been well evaluated, and further studies are needed to investigate the role of $\mathrm{nAChR}$ in context-specific regulation of UPR signaling upon nicotine treatment in different tissues.

Our results further demonstrated that nicotine regulated the DNA binding ability and activity of the YAP-TEAD transcriptional complex through $\alpha 7-n A C h R-A k t$ signaling. The YAP-TEAD complex is normally involved in the regulation of cell growth, proliferation, and organ development [42]. However, the overexpression of YAP has been observed in 
multiple types of cancer, including OSCC, liver cancer, colon cancer, and lung cancer [43]. In addition, YAP has been reported to be a crucial driver of cancer cell proliferation, invasion, migration, metastasis, and resistance to anti-cancer therapies [44]. Clinically, YAP expression has been shown to be significantly higher in OSCC tissues compared to adjacent normal tissues, and increased nuclear-diffused staining of YAP has been significantly associated with poor differentiation in OSCC tissues [45]. Furthermore, the expression of YAP has been positively correlated with smoking status in patients with esophageal squamous carcinoma [33]. Several oncogenes have been reported to be the downstream targets of YAP by interacting with TEAD. For example, vimentin has been shown to be a direct target of the YAP-TEAD complex, which is an intermediate filament protein that plays a role in cell motility and adhesion during EMT [46]. In addition, the YAP-TEAD complex has been demonstrated to increase the expression of the anti-apoptotic molecule, Bcl-2, leading to resistance to cell apoptosis in OSCC [45]. Notably, our results showed that nicotine could induce BiP expression via activation of YAP, and that knockdown of YAP expression diminished the nicotine-stimulated expression of BiP in OSCC. Therefore, our findings provide evidence that the YAP-TEAD complex functions as a downstream effector of $\alpha 7-\mathrm{nAChR}$ signaling, and that this is involved in the nicotine-induced expression of $\mathrm{BiP}$ and tumor progression in OSCC.

Previous studies have reported controversial results regarding the role of BiP in OSCC progression. BiP has been positively associated with OSCC malignant behaviors $[17,18]$. For example, BiP has been shown to be overexpressed in oral cancer cell lines compared to normal oral keratinocytes. In addition, knockdown of BiP has been shown to remarkably decrease cell growth, migratory and invasive abilities [17]. Xia et al. reported that OSCC tissues showed significantly higher expressions of BiP than normal oral tissues and that the expression of BiP was positively associated with clinicopathological parameters, including tumor size, pathological stage, histological grade, lymphatic metastasis, and distant metastasis in OSCC patients [18]. On the other hand, Huang et al. showed that weakly expressed BiP was significantly correlated with tumor-node-metastasis (TNM) stage and neck lymph node metastasis in patients with OSCC [47]. These contradictory findings regarding the role of BiP in OSCC may be explained by differences in subcellular localization and time-dependent expression of $\mathrm{BiP}$ [48]. Recent evidence has shown that $\mathrm{BiP}$ is typically localized in ER, but that in some circumstances BiP can also be secreted or relocate to outside the cytoplasm, nucleus, mitochondria, and cell membrane [49]. Inflammatory cytokines and the ER stress inducer, thapsigargin, have been shown to induce BiP translocation to the plasma membrane in pancreatic $\beta$-cells and human embryo kidney fibroblast cells, respectively $[50,51]$. The overexpression of $\mathrm{BiP}$ has also been shown to promote the relocation of BiP to the cell surface in the absence of ER stress [51]. Anti-cancer drugs such as the pan-Bcl-2 inhibitor obatoclax (OBX) have been shown to strongly stimulate BiP translocation to the cell membrane in multiple myeloma (MM) cells [52]. In addition, the nuclear localization of $\mathrm{BiP}$ has been shown to be markedly higher in lung adenocarcinoma compared with normal lung tissues [53]. Notably, cigarette smoking may also influence the subcellular localization of $\mathrm{BiP}$, as a previous study has reported increased secretion of $\mathrm{BiP}$ into bronchoalveolar lavage fluid (BALF) in chronic cigarette smokers [54]. We also noted that BiP can also translocate to the cell surface and the nucleus in OSCC tissues from mice (Figure S1). Depending on the different subcellular compartments of BiP, there may be diverse induction of intracellular signaling pathways and stimulation of pro-apoptotic or pro-survival responses in cancer. For example, cell surface BiP acts as a multifunctional receptor, and it has been demonstrated to be involved in the stimulation of cell proliferation, angiogenesis, and therapeutic resistance via activation of PI3K/Akt signaling in cancer [55]. In addition, oral cancer cells expressing cell surface BiP have been shown to have cancer stemness properties and radioresistance [56]. Conversely, interactions of cell surface $\mathrm{BiP}$ with ligands, Kringle 5 and Par-4, have been shown to potentially lead to activation of pro-apoptotic pathways in tumors and endothelial cells [55]. Kern et al. reported that the secretion of BiP conferred drug resistance in myeloma and endothelial cells and increased 
cell proliferation of colon cancer cells $[57,58]$. Furthermore, the kinetics of BiP expression may also affect the role of this molecule in cancer. In esophageal cancer, a strong BiP expression has been observed in the early and advanced stage rather than the middle stage [59]. In the present study, our findings provide scientific evidence that BiP plays an oncogenic role in mediating the malignant behaviors of OSCC after nicotine exposure. However, to clarify the role of BiP in OSCC upon nicotine treatment, further investigations of the subcellular distribution and dynamic expression of $\mathrm{BiP}$ are needed.

In conclusion, our study showed that nicotine increased the malignant behaviors of OSCC cells, including EMT change, migratory and invasive abilities, by upregulating $\mathrm{BiP}$ expression (Figure 7). Mechanistically, the effect of nicotine on the stimulation of $\mathrm{BiP}$ expression was through $\alpha 7-n A C h R-A k t$ signaling, followed by activation of the YAP-TEAD transcriptional complex. These findings provide a novel insight into the pathophysiological mechanisms of nicotine-induced oral cancer progression. Furthermore, our results may provide a potential therapeutic target molecule in nicotine-medicated oral cancer malignancy, which may improve the therapeutic outcomes of patients with tobacco-associated cancers.
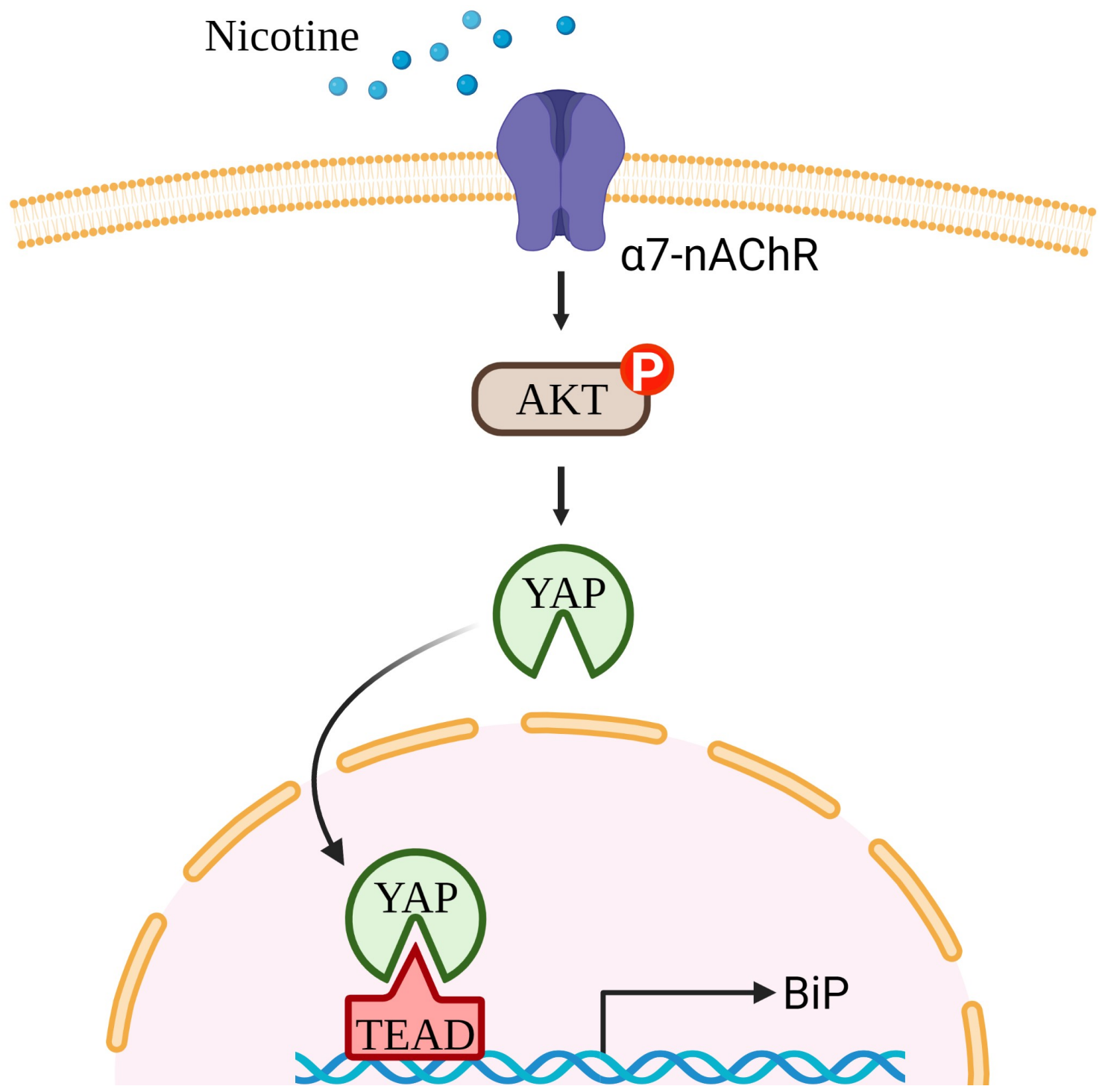

Figure 7. Nicotine stimulated OSCC malignancy through YAP-dependent BiP induction. Nicotine promoted malignant behaviors of OSCC, including EMT change, migration, and invasion, via inducing BiP expression. Mechanistically, nicotine increased BiP expression through $\alpha 7-n A C h R-A k t$ signaling and subsequent YAP dephosphorylation and nuclear translocation. Nuclear YAP together with TEAD increased HSPA5 promoter activity in OSCC cells after nicotine treatment. 
Supplementary Materials: The following are available online at https://www.mdpi.com/article/10 $.3390 /$ cells10082080/s1, Figure S1: Subcellular distribution of BiP in OSCC tissues from mice.

Author Contributions: Conceptualization, C.-Y.C., C.-H.L. and Y.-S.S.; methodology, Y.-C.C. and C.-H.L.; formal analysis, C.-Y.C., Y.-C.C., C.-C.H., S.-Y.L., A.C.-T.H. and C.-Y.Y.; investigation, C.-Y.C.; resources, Y.-T.C. and S.-G.S.; writing-original draft preparation, C.-Y.C.; writing-review and editing, C.-H.L. and Y.-S.S.; supervision, C.-H.L. and Y.-S.S.; project administration, Y.-S.S.; funding acquisition, Y.-S.S. All authors have read and agreed to the published version of the manuscript.

Funding: This research was funded by research grants from the Ministry of science and technology (MOST 108-2314-B-016-003-MY3), the National Defense Medical Center (MND-MAB-110-101), the Tri-Service General Hospital (TSGH-C04-109029, TSGH-C03-110023), and the Chi Mei Medical Center (CMNDMC10901), Taiwan.

Institutional Review Board Statement: The study was conducted according to the guidelines approved by the Institutional Animal Care and Use Committee at National Defense Medical Center (NDMC) (Taipei, Taiwan) (IACUC-18-354).

Informed Consent Statement: Not applicable.

Data Availability Statement: Not applicable.

Acknowledgments: We would like to acknowledge the Laboratory Animal Center of National Defense Medical Center (NDMC-LAC), Taiwan, for support in animal husbandry and medical care. The illustration was created with BioRender.com.

Conflicts of Interest: The authors declare no conflict of interest.

\section{References}

1. Jiang, X.; Wu, J.; Wang, J.; Huang, R. Tobacco and oral squamous cell carcinoma: A review of carcinogenic pathways. Tob. Induc. Dis. 2019, 17, 29. [CrossRef] [PubMed]

2. Kumar, M.; Nanavati, R.; Modi, T.G.; Dobariya, C. Oral cancer: Etiology and risk factors: A review. J. Cancer Res. Ther. 2016, 12, 458. [CrossRef] [PubMed]

3. Alsahafi, E.; Begg, K.; Amelio, I.; Raulf, N.; Lucarelli, P.; Sauter, T.; Tavassoli, M. Clinical update on head and neck cancer: Molecular biology and ongoing challenges. Cell Death Dis. 2019, 10, 540. [CrossRef] [PubMed]

4. Siegel, R.L.; Miller, K.D.; Jemal, A. Cancer statistics, 2019. CA Cancer J. Clin. 2019, 69, 7. [CrossRef]

5. Harris, C.C. Tobacco smoking, E-cigarettes, and nicotine harm. Proc. Natl. Acad. Sci. USA 2018, 115, 1406. [CrossRef] [PubMed]

6. Xu, J.; Huang, H.; Pan, C.; Zhang, B.; Liu, X.; Zhang, L. Nicotine inhibits apoptosis induced by cisplatin in human oral cancer cells. Int. J. Oral Maxillofac. Surg. 2007, 36, 739. [CrossRef] [PubMed]

7. Nishioka, T.; Tada, H.; Ibaragi, S.; Chen, C.; Sasano, T. Nicotine exposure induces the proliferation of oral cancer cells through the alpha subunit of the nicotinic acetylcholine receptor. Biochem. Biophys. Res. Commun. 2019, 509, 514. [CrossRef]

8. Wang, M.; Niu, W.; Qi, M.; Chen, H.; Zhang, M.; Wang, C.; Ge, L.; Yang, J.; Miao, C.; Shi, N.; et al. Nicotine promotes cervical metastasis of oral cancer by regulating peroxiredoxin 1 and epithelial-mesenchymal transition in mice. Onco Targets Ther. 2019, 12, 3327. [CrossRef] [PubMed]

9. Jorgensen, E.; Stinson, A.; Shan, L.; Yang, J.; Gietl, D.; Albino, A.P. Cigarette smoke induces endoplasmic reticulum stress and the unfolded protein response in normal and malignant human lung cells. BMC Cancer 2008, 8, 229. [CrossRef]

10. Wong, M.K.; Holloway, A.C.; Hardy, D.B. Nicotine Directly Induces Endoplasmic Reticulum Stress Response in Rat Placental Trophoblast Giant Cells. Toxicol. Sci. 2016, 151, 23. [CrossRef] [PubMed]

11. Schonthal, A.H. Endoplasmic reticulum stress: Its role in disease and novel prospects for therapy. Scientifica 2012, $2012,857516$. [CrossRef] [PubMed]

12. Luo, B.; Lee, A.S. The critical roles of endoplasmic reticulum chaperones and unfolded protein response in tumorigenesis and anticancer therapies. Oncogene 2013, 32, 805. [CrossRef] [PubMed]

13. Urra, H.; Dufey, E.; Avril, T.; Chevet, E.; Hetz, C. Endoplasmic Reticulum Stress and the Hallmarks of Cancer. Trends Cancer 2016, 2, 252. [CrossRef]

14. Li, Z.; Li, Z. Glucose regulated protein 78: A critical link between tumor microenvironment and cancer hallmarks. Biochim. Biophys. Acta 2012, 1826, 13. [CrossRef]

15. Lin, C.Y.; Chen, W.H.; Liao, C.T.; Chen, I.H.; Chiu, C.C.; Wang, H.M.; Yen, T.C.; Lee, L.Y.; Chang, J.T.; Cheng, A.J. Positive association of glucose-regulated protein 78 during oral cancer progression and the prognostic value in oral precancerous lesions. Head Neck 2010, 32, 1028. [CrossRef]

16. Dauer, P.; Sharma, N.S.; Gupta, V.K.; Durden, B.; Hadad, R.; Banerjee, S.; Dudeja, V.; Saluja, A.; Banerjee, S. ER stress sensor, glucose regulatory protein 78 (GRP78) regulates redox status in pancreatic cancer thereby maintaining "stemness". Cell Death Dis. 2019, 10, 132. [CrossRef] [PubMed] 
17. Chiu, C.C.; Lin, C.Y.; Lee, L.Y.; Chen, Y.J.; Kuo, T.F.; Chang, J.T.; Liao, C.T.; Wang, H.M.; Yen, T.C.; Shen, C.R.; et al. Glucoseregulated protein 78 regulates multiple malignant phenotypes in head and neck cancer and may serve as a molecular target of therapeutic intervention. Mol. Cancer Ther. 2008, 7, 2788. [CrossRef]

18. Xia, F.; Xu, J.C.; Zhang, P.; Zhang, Y.Y.; Zhang, Q.W.; Chao, Z.H.; Wang, F. Glucose-regulated protein 78 and heparanase expression in oral squamous cell carcinoma: Correlations and prognostic significance. World J. Surg. Oncol. 2014, 12, 121. [CrossRef]

19. Crowley-Weber, C.L.; Dvorakova, K.; Crowley, C.; Bernstein, H.; Bernstein, C.; Garewal, H.; Payne, C.M. Nicotine increases oxidative stress, activates NF-kappaB and GRP78, induces apoptosis and sensitizes cells to genotoxic/xenobiotic stresses by a multiple stress inducer, deoxycholate: Relevance to colon carcinogenesis. Chem. Biol. Interact. 2003, 145, 53. [CrossRef]

20. Repo, J.K.; Pesonen, M.; Mannelli, C.; Vahakangas, K.; Loikkanen, J. Exposure to ethanol and nicotine induces stress responses in human placental BeWo cells. Toxicol. Lett. 2014, 224, 264. [CrossRef] [PubMed]

21. Zhao, Y. The Oncogenic Functions of Nicotinic Acetylcholine Receptors. J. Oncol. 2016, 2016, 9650481. [CrossRef]

22. Singh, S.; Pillai, S.; Chellappan, S. Nicotinic acetylcholine receptor signaling in tumor growth and metastasis. J. Oncol. 2011, 2011, 456743. [CrossRef]

23. Wang, S.; Hu, Y. $\alpha 7$ nicotinic acetylcholine receptors in lung cancer. Oncol. Lett. 2018, 16, 1375. [CrossRef] [PubMed]

24. Zhang, M.; Zhao, Y.H.; Tang, X.F.; Hou, M. Effect of nicotine on the proliferation and cell apoptosis of oral squamous cell carcinoma SCC15 cells. Chin. J. Stomatol. 2012, 47, 233. (In Chinese) [CrossRef]

25. Wang, C.; Niu, W.; Chen, H.; Shi, N.; He, D.; Zhang, M.; Ge, L.; Tian, Z.; Qi, M.; Chen, T.; et al. Nicotine suppresses apoptosis by regulating $\alpha 7 \mathrm{nAChR} / \operatorname{Prx} 1$ axis in oral precancerous lesions. Oncotarget 2017, 8, 75065. [CrossRef]

26. Ishibashi, T.; Morita, S.; Kishimoto, S.; Uraki, S.; Takeshima, K.; Furukawa, Y.; Inaba, H.; Ariyasu, H.; Iwakura, H.; Furuta, H.; et al. Nicotinic acetylcholine receptor signaling regulates inositol-requiring enzyme $1 \alpha$ activation to protect $\beta$-cells against terminal unfolded protein response under irremediable endoplasmic reticulum stress. J. Diabetes Investig. 2020, 11, 801. [CrossRef]

27. Davis, R.; Rizwani, W.; Banerjee, S.; Kovacs, M.; Haura, E.; Coppola, D.; Chellappan, S. Nicotine promotes tumor growth and metastasis in mouse models of lung cancer. PLoS ONE 2009, 4, e7524. [CrossRef]

28. Underwood, P.W.; Zhang, D.Y.; Cameron, M.E.; Gerber, M.H.; Delitto, D.; Maduka, M.U.; Cooper, K.J.; Han, S.; Hughes, S.J.; Judge, S.M.; et al. Nicotine Induces IL-8 Secretion from Pancreatic Cancer Stroma and Worsens Cancer-Induced Cachexia. Cancers 2020, 12, 329. [CrossRef]

29. Lee, A.S. Glucose-regulated proteins in cancer: Molecular mechanisms and therapeutic potential. Nat. Rev. Cancer 2014, 14, 263. [CrossRef] [PubMed]

30. Cheng, W.-L.; Chen, K.-Y.; Lee, K.-Y.; Feng, P.-H.; Wu, S.-M. Nicotinic-nAChR signaling mediates drug resistance in lung cancer. J. Cancer 2020, 11, 1125. [CrossRef]

31. Omori, H.; Nishio, M.; Masuda, M.; Miyachi, Y.; Ueda, F.; Nakano, T.; Sato, K.; Mimori, K.; Taguchi, K.; Hikasa, H.; et al. YAP1 is a potent driver of the onset and progression of oral squamous cell carcinoma. Sci. Adv. 2020, 6, eaay3324. [CrossRef] [PubMed]

32. Yu, F.-X.; Zhao, B.; Guan, K.-L. Hippo Pathway in Organ Size Control, Tissue Homeostasis, and Cancer. Cell $2015,163,811$. [CrossRef]

33. Zhao, Y.; Zhou, W.; Xue, L.; Zhang, W.; Zhan, Q. Nicotine activates YAP1 through nAChRs mediated signaling in esophageal squamous cell cancer (ESCC). PLoS ONE 2014, 9, e90836. [CrossRef]

34. Lin, K.C.; Park, H.W.; Guan, K.L. Regulation of the Hippo Pathway Transcription Factor TEAD. Trends Biochem. Sci. 2017, $42,862$. [CrossRef] [PubMed]

35. Chaturvedi, P.; Singh, A.; Chien, C.-Y.; Warnakulasuriya, S. Tobacco related oral cancer. BMJ 2019, 365, 12142. [CrossRef]

36. Sanner, T.; Grimsrud, T.K. Nicotine: Carcinogenicity and Effects on Response to Cancer Treatment-A Review. Front. Oncol. 2015, 5, 196. [CrossRef]

37. Lam, D.C.; Girard, L.; Ramirez, R.; Chau, W.S.; Suen, W.S.; Sheridan, S.; Tin, V.P.; Chung, L.P.; Wong, M.P.; Shay, J.W.; et al. Expression of nicotinic acetylcholine receptor subunit genes in non-small-cell lung cancer reveals differences between smokers and nonsmokers. Cancer Res. 2007, 67, 4638. [CrossRef] [PubMed]

38. Schaal, C.; Chellappan, S. Nicotine-Mediated Regulation of Nicotinic Acetylcholine Receptors in Non-Small Cell Lung Adenocarcinoma by E2F1 and STAT1 Transcription Factors. PLoS ONE 2016, 11, e0156451. [CrossRef] [PubMed]

39. Dinicola, S.; Morini, V.; Coluccia, P.; Proietti, S.; D’Anselmi, F.; Pasqualato, A.; Masiello, M.G.; Palombo, A.; De Toma, G.; Bizzarri, M.; et al. Nicotine increases survival in human colon cancer cells treated with chemotherapeutic drugs. Toxicol. In Vitro 2013, 27, 2256. [CrossRef]

40. Zhang, C.; Yu, P.; Zhu, L.; Zhao, Q.; Lu, X.; Bo, S. Blockade of alpha7 nicotinic acetylcholine receptors inhibit nicotine-induced tumor growth and vimentin expression in non-small cell lung cancer through MEK/ERK signaling way. Oncol. Rep. 2017, 38, 3309. [CrossRef]

41. Srinivasan, R.; Richards, C.I.; Xiao, C.; Rhee, D.; Pantoja, R.; Dougherty, D.A.; Miwa, J.M.; Lester, H.A. Pharmacological chaperoning of nicotinic acetylcholine receptors reduces the endoplasmic reticulum stress response. Mol. Pharmacol. 2012, 81, 759. [CrossRef] [PubMed]

42. Holden, J.K.; Cunningham, C.N. Targeting the Hippo Pathway and Cancer through the TEAD Family of Transcription Factors. Cancers 2018, 10, 81. [CrossRef]

43. Zhao, B.; Li, L.; Lei, Q.; Guan, K.L. The Hippo-YAP pathway in organ size control and tumorigenesis: An updated version. Genes Dev. 2010, 24, 862. [CrossRef] [PubMed] 
44. Thompson, B.J. YAP/TAZ: Drivers of Tumor Growth, Metastasis, and Resistance to Therapy. BioEssays News Rev. Mol. Cell. Dev. Biol. 2020, 42, e1900162. [CrossRef]

45. Chen, X.; Gu, W.; Wang, Q.; Fu, X.; Wang, Y.; Xu, X.; Wen, Y. C-MYC and BCL-2 mediate YAP-regulated tumorigenesis in OSCC. Oncotarget 2017, 9, 668. [CrossRef]

46. Liu, Y.; Wang, G.; Yang, Y.; Mei, Z.; Liang, Z.; Cui, A.; Wu, T.; Liu, C.Y.; Cui, L. Increased TEAD4 expression and nuclear localization in colorectal cancer promote epithelial-mesenchymal transition and metastasis in a YAP-independent manner. Oncogene 2016, 35, 2789. [CrossRef]

47. Huang, T.T.; Chen, J.Y.; Tseng, C.E.; Su, Y.C.; Ho, H.C.; Lee, M.S.; Chang, C.T.; Wong, Y.K.; Chen, H.R. Decreased GRP78 protein expression is a potential prognostic marker of oral squamous cell carcinoma in Taiwan. J. Formos. Med. Assoc. 2010, 109, 326 [CrossRef]

48. Ronco, C.; Rocchi, S.; Benhida, R. Expression level of GRP78/BiP as a predictor of favorable or unfavorable outcomes in cancer patients. Mediastinum 2018, 2, 26. [CrossRef]

49. Casas, C. GRP78 at the Centre of the Stage in Cancer and Neuroprotection. Front. Neurosci. 2017, 11, 177. [CrossRef] [PubMed]

50. Vig, S.; Buitinga, M.; Rondas, D.; Crèvecoeur, I.; van Zandvoort, M.; Waelkens, E.; Eizirik, D.L.; Gysemans, C.; Baatsen, P.; Mathieu, C.; et al. Cytokine-induced translocation of GRP78 to the plasma membrane triggers a pro-apoptotic feedback loop in pancreatic beta cells. Cell Death Dis. 2019, 10, 309. [CrossRef]

51. Zhang, Y.; Liu, R.; Ni, M.; Gill, P.; Lee, A.S. Cell surface relocalization of the endoplasmic reticulum chaperone and unfolded protein response regulator GRP78/BiP. J. Biol. Chem. 2010, 285, 15065. [CrossRef] [PubMed]

52. Ramakrishnan, V.; Gomez, M.; Prasad, V.; Kimlinger, T.; Painuly, U.; Mukhopadhyay, B.; Haug, J.; Bi, L.; Rajkumar, S.V.; Kumar, S. Smac mimetic LCL161 overcomes protective ER stress induced by obatoclax, synergistically causing cell death in multiple myeloma. Oncotarget 2016, 7, 56253. [CrossRef]

53. Ogata, S.; Kameda, K.; Kono, T.; Ozeki, Y.; Hashimoto, H.; Tominaga, S.; Nakanishi, K. Expressions of ATF6, XBP1, and GRP78 in normal tissue, atypical adenomatous hyperplasia, and adenocarcinoma of the lung. Hum. Pathol. 2019, 83, 22. [CrossRef]

54. Aksoy, M.O.; Kim, V.; Cornwell, W.D.; Rogers, T.J.; Kosmider, B.; Bahmed, K.; Barrero, C.; Merali, S.; Shetty, N.; Kelsen, S.G. Secretion of the endoplasmic reticulum stress protein, GRP78, into the BALF is increased in cigarette smokers. Respir. Res. 2017, 18, 78. [CrossRef] [PubMed]

55. Ni, M.; Zhang, Y.; Lee, A.S. Beyond the endoplasmic reticulum: Atypical GRP78 in cell viability, signalling and therapeutic targeting. Biochem. J. 2011, 434, 181. [CrossRef] [PubMed]

56. Wu, M.-J.; Jan, C.-I.; Tsay, Y.-G.; Yu, Y.-H.; Huang, C.-Y.; Lin, S.-C.; Liu, C.-J.; Chen, Y.-S.; Lo, J.-F.; Yu, C.-C. Elimination of head and neck cancer initiating cells through targeting glucose regulated protein78 signaling. Mol. Cancer 2010, 9, 283. [CrossRef] [PubMed]

57. Kern, J.; Untergasser, G.; Zenzmaier, C.; Sarg, B.; Gastl, G.; Gunsilius, E.; Steurer, M. GRP-78 secreted by tumor cells blocks the antiangiogenic activity of bortezomib. Blood 2009, 114, 3960. [CrossRef] [PubMed]

58. Fu, R.; Yang, P.; Wu, H.L.; Li, Z.W.; Li, Z.Y. GRP78 secreted by colon cancer cells facilitates cell proliferation via PI3K/Akt signaling. Asian Pac. J. Cancer Prev. 2014, 15, 7245. [CrossRef] [PubMed]

59. Langer, R.; Feith, M.; Siewert, J.R.; Wester, H.J.; Hoefler, H. Expression and clinical significance of glucose regulated proteins GRP78 (BiP) and GRP94 (GP96) in human adenocarcinomas of the esophagus. BMC Cancer 2008, 8, 70. [CrossRef] [PubMed] 